\title{
Enhanced turbulent mixing induced by strong wind on the South China Sea shelf
}

\author{
Yanwei Zhang $\cdot$ Jiwei Tian
}

Received: 30 October 2012 / Accepted: 26 February 2014 / Published online: 27 April 2014

(C) The Author(s) 2014. This article is published with open access at Springerlink.com

\begin{abstract}
Integrated observations were made on the South China Sea shelf at $19^{\circ} 37^{\prime} \mathrm{N}, 112^{\circ} 04^{\prime} \mathrm{E}$, under strong wind and heavy raining weather conditions in August 2005. Current data were obtained using a moored $150-\mathrm{kHz}$ Acoustic Doppler Current Profiler, turbulent kinetic energy dissipation rate were measured with TurboMapII, and temperature was recorded by thermistor chains. Both the mixed layer thickness and the corresponding mean dissipation rate increased after the strong wind bursts. Average surface mixed layer thickness was $13.4 \mathrm{~m}$ pre-wind and $22.4 \mathrm{~m}$ post-wind, and the average turbulent dissipation rate in the mixed layer pre-wind and post-wind were $4.26 \times 10^{-7}$ and $1.09 \times 10^{-6} \mathrm{Wkg}^{-1}$, respectively. The post-wind dissipation rate was 2.5 times larger than the pre-wind dissipation rate in the interior layer and four times larger in the intermediate water column. Spectra and vertical mode analysis revealed that near-inertial motion post-wind, especially with high modes, was strengthened and propagated downward toward the intermediate layer. The downward group velocity
\end{abstract}

Responsible Editor: Pierre De Mey

This work was funded by Chinese National Natural Science Foundation (No. 41106013) and Program 973 (No. 2014CB745003) and Major Program of Chinese National Natural Science Foundation (No. 91028008, 91128206).

Y. Zhang $(\varangle)$

State Key Lab of Marine Geology, Tongji University, No. 1239

Siping Road, Shanghai, 200092, China

e-mail: ywzhang@tongji.edu.cn

J. Tian $(\bowtie)$

Physical Oceanography Laboratory, Ocean University of China,

No. 238 Songling Road, Qingdao, 266100, China

e-mail: tianjw@ouc.edu.cn of near-inertial current was about $8.1 \times 10^{-5} \mathrm{~ms}^{-1}$ during the strong wind bursts. The mean percentage of wind work transmitted into the intermediate layer is about $4.2 \%$. The ratio of post-wind high-mode energy to total horizontal kinetic energy increased below the surface mixed layer, which would have caused instabilities and result in turbulent mixing. Based on these data, we discuss a previous parameterization that relates dissipation rate, stratification, and shear variance calculated from baroclinic currents with high modes (higher than mode 1) which concentrate a large fraction of energy.

Keywords Enhanced mixing $\cdot$ Strong wind $\cdot$ Near-inertial current $\cdot$ High-mode shear variance

\section{Introduction}

Ocean mixing is an important process in controlling the distribution of physical properties of water masses, ocean circulation, nutrient fluxes, and concentration of particulate matter (Sandstrom and Elliot 1984; Wunsch and Ferrari 2004; Sharples et al. 2001). Numerous studies have focused on the role of internal tides in triggering the mixing in coastal regions (Garrett 2003; Moum et al. 2003; Nash et al. 2004). In addition to internal tides, wind-generated internal waves also lead to strong mixing (Gill 1984; D'Asaro et al. 1995). The wind blowing on the sea surface generates mixed layer currents that rotate at local inertial frequency that can force downward-propagating near-inertial waves (D'Asaro et al. 1995). Wind-forced near-inertial waves, which frequently are observed both in the open ocean and in coastal seas (D'Asaro and Perkins 1984; Watanabe and Hibiya 2002; MacKinnon and Gregg 2005a; Alford et al. 2012), propagate downward and thus represent a major flux 
of energy into the ocean that is available for the generation of turbulence and mixing (Kunze 1985; van der Lee and Umlauf 2011).

The results documented in our study and those of other studies indicate that strong turbulent mixing occurs below the base of the mixed layer during the strong wind bursts (Grant and Belcher 2011; Dohan and Davis 2011). The magnitude of the enhanced mixing that is correlated with the near-inertial waves should be related to the energy flux that propagates from sea surface to the interior (Alford 2001). Besides, the correlation between the near-inertial waves and strong surface forcing is lagged in time. It is found that the gradual propagation of storm induced inertial waves into the thermocline that lasted many days after the initiation of the storm based on the Ocean Storm Experiment in the northeast Pacific Ocean (Qi et al. 1995). Three cycles of a single, energetic, downward-propagating near-inertial wave associated with enhanced mixing were observed in the Banda Sea (Alford and Gregg 2001). The data indicated that the mixing was coherent at the $95 \%$ confidence level with both shear and stratification which were coincident with the high winds. MacKinnon and Gregg (2005b) reported that the largest turbulent dissipation away from boundaries was coincident with shear from lower-mode near-inertial waves generated by passing storms. They also argued that turbulent dissipation rates increased with both shear and stratification which is also confirmed by the measurements observed in the Baltic Sea (van der Lee and Umlauf 2011); this differs from Gregg-Henyey scaling (Gregg 1989) used for the open ocean. To study the generation and evolution of inertial waves and mixing in response to local high winds, D'Asaro (2003) used airdeployed neutrally buoyant floats to observe mixing beneath a storm. Cuypers et al. (2013) observed a marked increase of heating rate due to enhanced mixing in the thermocline and interior ocean which was generated by storms. However, comparatively little work has been focused on turbulent dissipation related with near-inertial waves in coastal regions under high wind conditions (MacKinnon and Gregg 2005b). The main reason for this lack of information is that direct observations of turbulent energy dissipation are sparse.

The ocean current on the continental shelf in the South China Sea (SCS) is influenced by monsoonal typhoons which frequently occur in summer. Thus, the SCS provides a good place to examine the relation between near-inertial waves and the accompanied enhanced turbulent dissipation. To evaluate the impact of wind-forced near-inertial waves on ocean mixing through shear instability on the SCS shelf, an integrated experiment was performed at $19^{\circ} 37^{\prime}$ $\mathrm{N}, 112^{\circ} 04^{\prime} \mathrm{E}$ in August 2005. We focused on understanding the dynamic relationships between turbulent mixing, near-inertial current shear, and stratification and on how the enhanced turbulent mixing penetrate away from the surface and bottom boundaries. We begin by introducing the field observations in Section 1 and then describe the relevant background water properties and meteorological forces in Section 2. In Section 3, we describe the observed turbulent mixing in detail. We then explain our analysis of the vertical propagation of near-inertial waves using vector spectral analysis in Section 4. We present a summary and discussion on the possible parameterization method for the dissipation rate in Section 5.

\section{Data and methods}

To analyze the distinct characteristics of ocean mixing caused by strong wind, we made field observation during summer when typhoons frequently occur in the SCS. From 5 to 18 August 2005, we obtained microstructure profiles and measurements of current velocity, temperature, salinity, and density near Wenchang in Hainan Province (Fig. 1). The topography of the observation site is fairly smooth with an average depth of $117 \mathrm{~m}$. Wind speed is obtained from National Centers for Environmental Prediction (NCEP) reanalysis wind data set which is four times daily. Wind data of four grids nearest to our observation site were used to interpolate to the wind speed analyzed in this paper (Fig. 2a). The details about the deployment are as follows:

1. The primary instrument for microstructure measurements was TurboMapII, which was a loosely tethered, free-falling instrument that was ballasted to fall at about $0.5 \mathrm{~ms}^{-1}$. TurboMapII was equipped with highresolution sensors for measuring microstructure current shear $d u / d z$ and the temperature gradient $d T / d z$ at $256 \mathrm{~Hz}$ and with standard CTD (conductivitytemperature-depth) sensors. TurboMapII can provide temperature, salinity, and density (Fig. 2) and can also provide a direct calculation of the turbulent kinetic energy dissipation rate $\epsilon$ (Wolk et al. 2002). TurboMapII was carried aboard a 200-hp ship; this was such a small vessel that it eliminated the wake impact on the surface turbulence observations. On 10 August, the ship was forced into port due to the imminent arrival of strong wind bursts and heavy rain, and we returned to the observation site on 14 August. TurboMapII took measurements approximately every hour, resulting in 214 microstructure profiles. For this experiment, microstructure measurements for the bottom layer were not made because the sensors would be broken when they touched the seabed. Most of the profiles extended as deep as to the intermediate layer (60-80 m, introduced in Section 3). 
Fig. 1 Map of the north South China Sea. The green line marked with square shows the track of Typhoon Sanvu. The black pentagram shows the observation site $\left(19^{\circ} 37^{\prime} \mathrm{N}\right.$, $112^{\circ} 04^{\prime}$ E). The depth of this location is about $117 \mathrm{~m}$

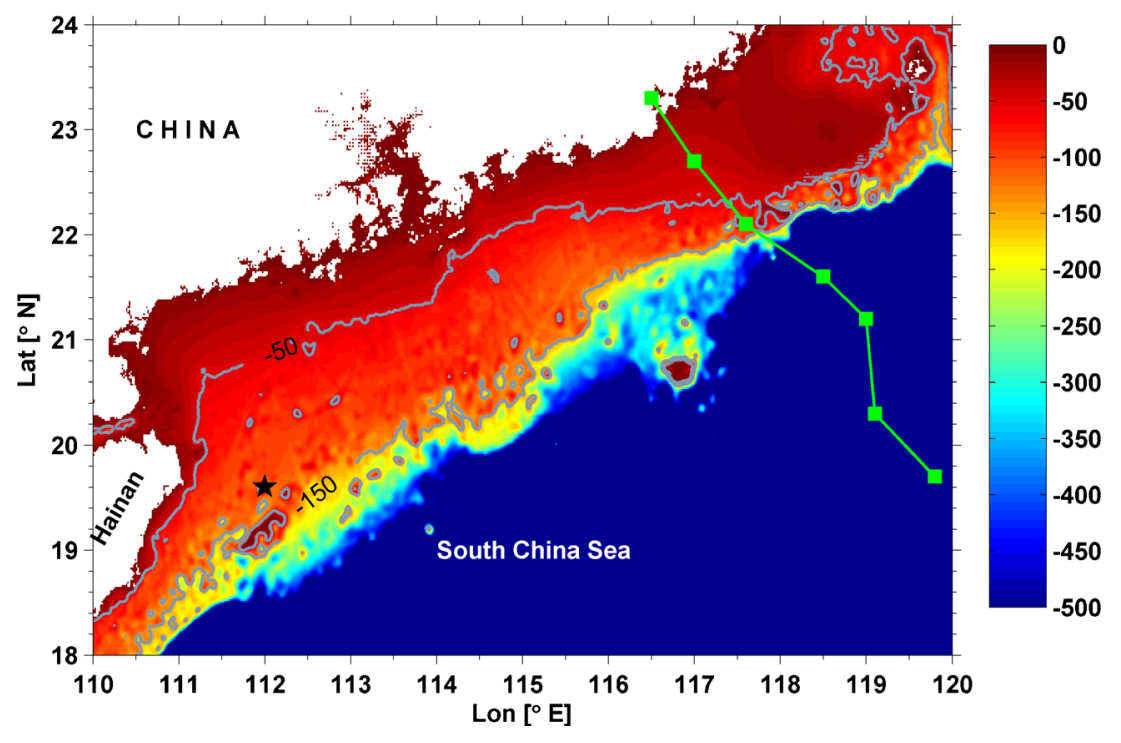

2. A cable equipped with thermistors and salinity sensors was moored at Wenchang 13-1 oil drilling rig. The upper side of the cable was fixed on the rig, and the lower side was anchored at the bottom by an $800-\mathrm{kg}$ iron weight. In total, 24 thermistor sensors and 5 temperature-salinity sensors were deployed at different depths to record water temperature and salinity from 4 to 19 August 2005. The sampling time interval was $1 \mathrm{~min}$ and the depth interval was $2 \mathrm{~m}$ for thermistor sensors from 12 to $80 \mathrm{~m}$. The temperature data obtained from these thermistors can compensate for the temperature measurements obtained from the repeated microstructure
Fig. 2 a Wind, $\mathbf{b}$ temperature of pre-wind, $\mathbf{c}$ temperature of postwind, $\mathbf{d}$ salinity of pre-wind, $\mathbf{e}$ salinity of post-wind, $\mathbf{f}$ density of pre-wind, $\mathbf{g}$ density of postwind. Temperature, salinity, and density are from the TurboMapII measurements. The black thick line is for the surface mixed layer depth calculated from the density differences which is less than $0.125 \mathrm{kgm}^{-3}$ from the sea surface minimal density
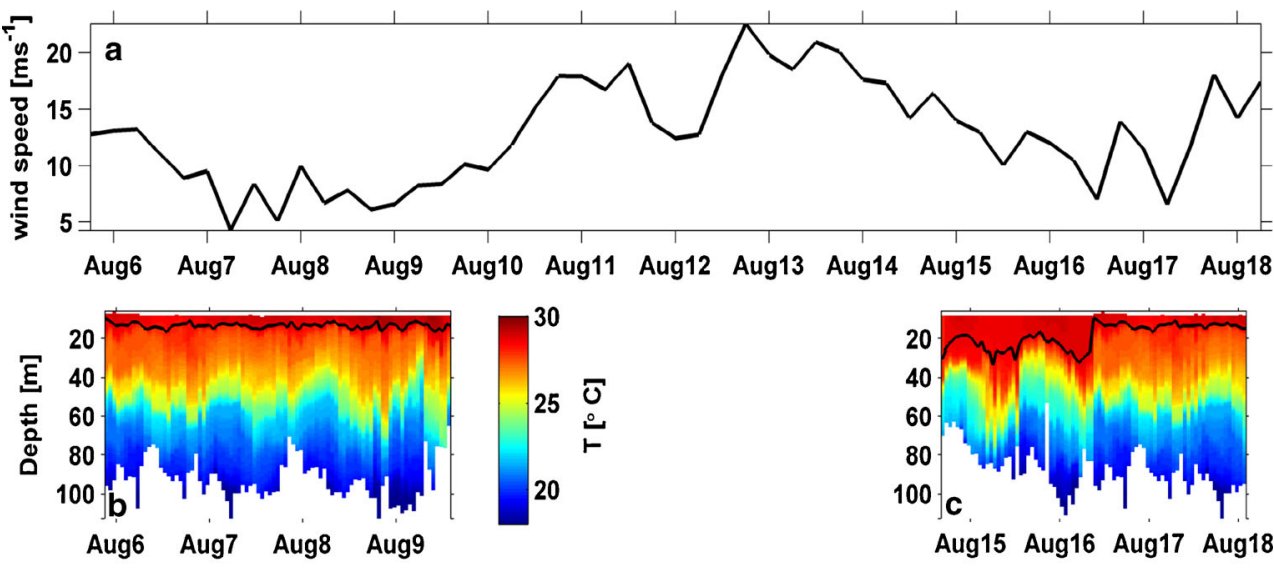

Aug15 Aug16 Aug17 Aug18
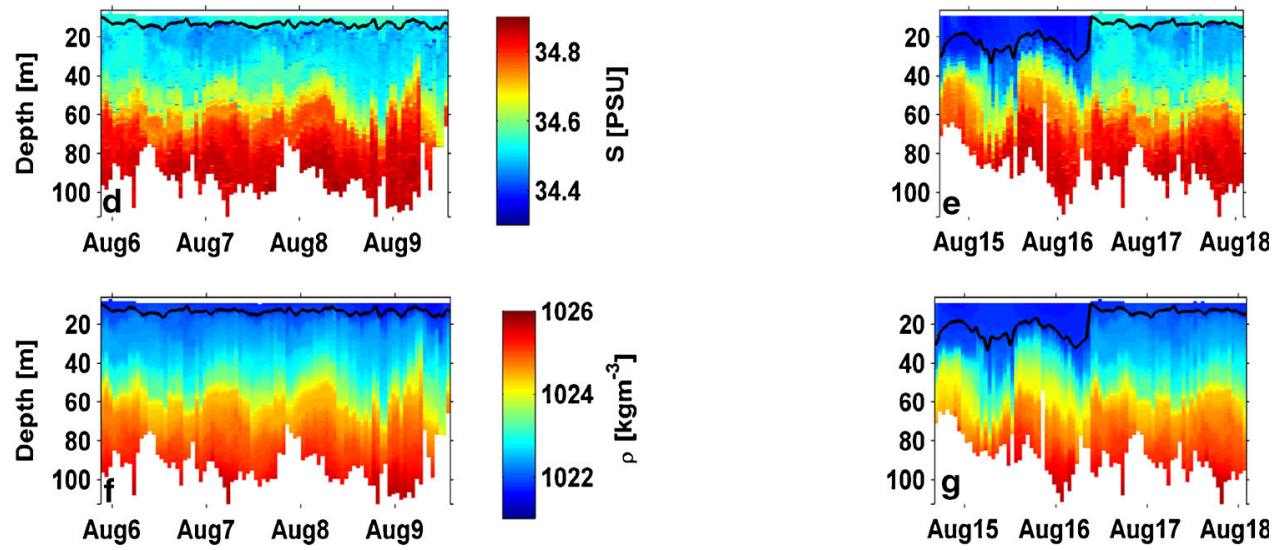
deployment. The moored temperature data at different depths were chosen to see the vertical temperature variations during the strong wind bursts (Fig. 3).

3. The current velocity data was recorded using one downlooking broadband $150 \mathrm{kHz}$ ADCP (Acoustic Doppler Current profiler), which was moored at Wenchang131 oil drilling rig. The oil rig was located about $200 \mathrm{~m}$ away from the microstructure observation site. Throughout the entire month of August 2005, we obtained a time series of current velocity at 10 -min intervals with 2-m vertical bins between 8 and $110 \mathrm{~m}$ (Figs. 4a and 5a). One instrumental artifact should be mentioned here. The current velocity at $34 \mathrm{~m}$ depth is quite different, and the corresponding echo intensity at $34 \mathrm{~m}$ was strong without a clear reason. This results in high shear variance which was inconsistent with turbulent dissipation rate. In the following analysis, current velocity data at $34 \mathrm{~m}$ was removed and interpolated using linear method. Baroclinic velocity was computed by removing the depth-mean value, and shear variance $\left(S^{2}\right)$ was computed by first-differencing composite velocity over 4-m intervals in terms of $S^{2}=$ $(d u / d z)^{2}+(d v / d z)^{2}$, where $u$ and $v$ are horizontal baroclinic current velocity components, and $\mathrm{z}$ is depth.

\subsection{Background conditions on the SCS shelf}

The current motions in the SCS are influenced primarily by monsoon wind (also called the East-Asia tropic monsoon). From April to August, the weaker southwesterly summer monsoon winds result in a wind stress of over $0.1 \mathrm{Nm}^{-2}$ that drives a northward coastal jet and anticyclonic circulation in the SCS. From November to March, the stronger northeasterly winter monsoon winds correspond to a maximum wind stress of nearly $0.3 \mathrm{Nm}^{-2}$, which causes a southward coastal jet and cyclonic circulation in the SCS (Chu et al. 1999). The transitional periods are marked by highly variable winds and surface currents, that usually are accompanied with rapid stratification evolution in August. According to the marine disaster report provided by the State Oceanic Administration of the People's Republic of China, nine typhoons landed on coastal areas in China in 2005. The one that occurred during the course of this study was named Typhoon Sanvu. It formed as a tropical depression 320 nautical miles east-northeast of Borongan in Samar Island inside the Philippines on the morning of August 10 at 0000 UTC (based on data from NASA/GSFC). Sanvu became a tropical storm within $24 \mathrm{~h}$ and passed over a peninsula on the island of Luzon early on the morning of 12 August. It was upgraded to a typhoon before making landfall in China on 13 August. Sanvu rapidly dissipated after moving inland on 14 August. According to the track of Sanvu (Fig. 1) from Typhoon 2000's tracking chart (from Typhoon2000 Philippine typhoon website), Sanvu was around $800 \mathrm{~km}$ away from Wenchang 13-1 oil rig. However, because our observation site was on the left side of Sanvu's track, the effect from Sanvu was limited (Price 1981).

\subsection{Meteorological and water properties of the SCS during} this experiment

There were several strong wind bursts during the observation. The strongest one occurred between 10 August and 14 August. In order to make it clear, we define "pre-wind" as the time period before noon on 10 August and "postwind" as the time period after noon on 14 August. The periods between noon on 10 August and 14 August is "during wind." The average wind velocity was $9.1 \mathrm{~ms}^{-1}$ before the strong wind bursts and then increased obviously to mean value of $15.8 \mathrm{~ms}^{-1}$ during the strong wind burst(Fig. 2a), specifically during night on 9 August and 10 August. The strong wind with values larger than $18 \mathrm{~ms}^{-1}$ lasted continuously longer than $24 \mathrm{~h}$. Current velocity was faster during the bursts of strong wind that occurred between 10 and 14 August. On average, $u$ and $v$ near the sea surface during
Fig. 3 The distribution of moored temperature at different depths. The temperature gradients were large before the strong wind bursts, and the gradients decreased apparently when the wind was strong on 10 August, suggesting strong vertical mixing occurred

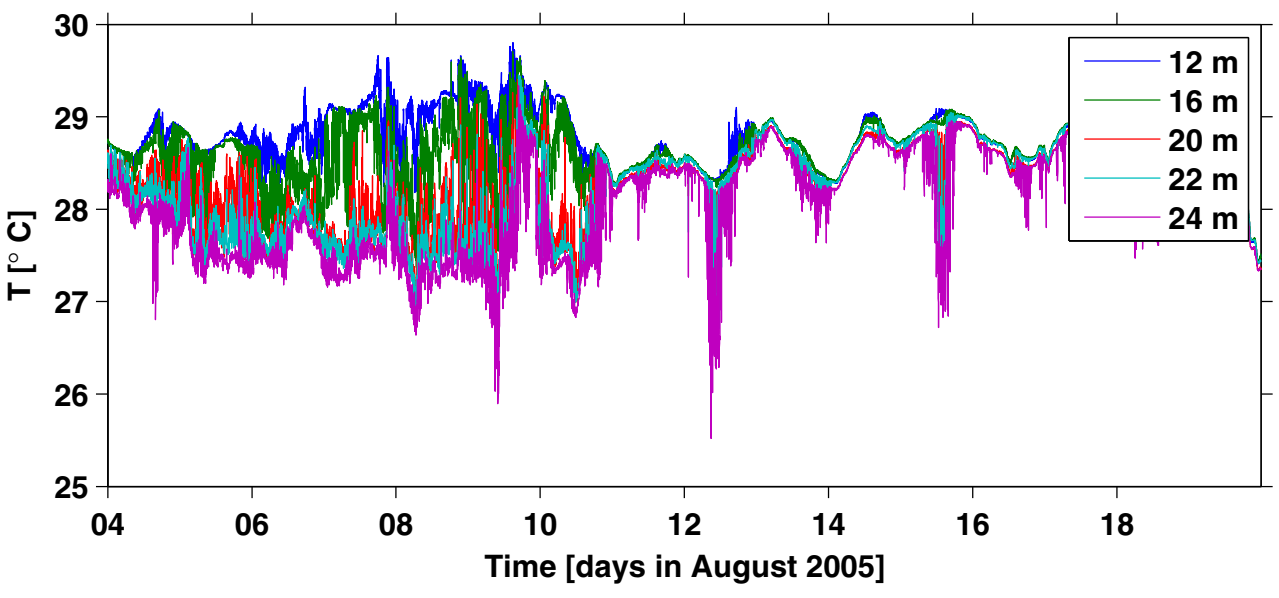


Fig. 4 The distribution of wind and zonal current velocity $u$ component (east-west direction). a Wind speed, $\mathbf{b}$ baroclinic current velocity with the depth-mean velocity removed, $\mathbf{c}$ near-inertial current velocity filtered from (b), d diurnal tide current filtered from $(\mathbf{b}), \mathbf{e}$ semidiurnal tide current filtered from (b). The black line in each panel shows the mixed layer depth computed from moored temperature difference a wind speed $\left[\mathrm{m} \mathrm{s}^{-1}\right]$

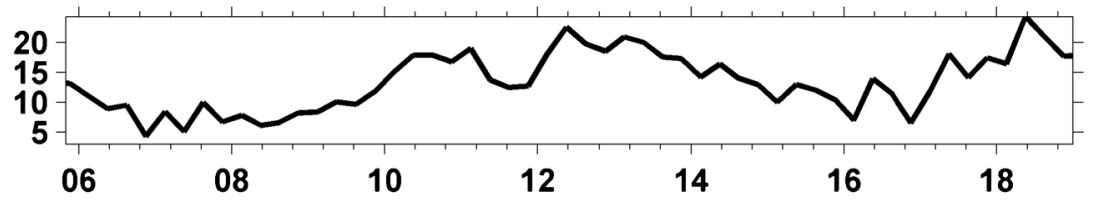

b Total Zonal baroclinic current $u_{b c}\left[\mathrm{~m} \mathrm{~s}^{-1}\right]$

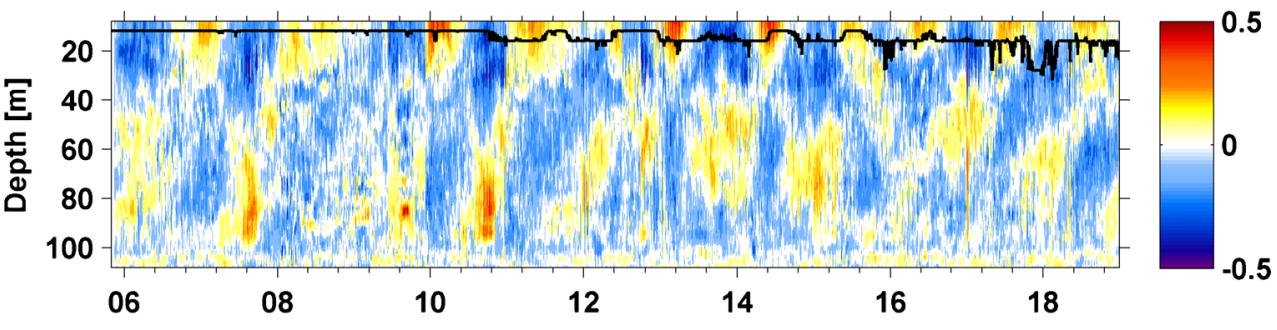

C Near-inertial current $u_{f}\left[\mathrm{~m} \mathrm{~s}^{-1}\right]$

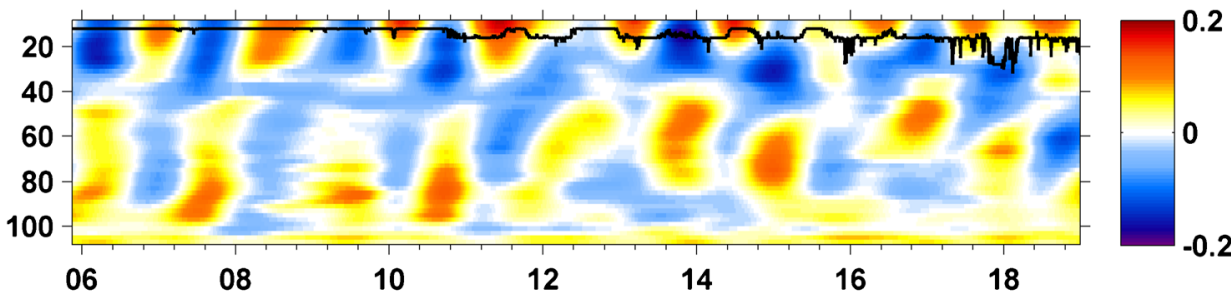

d Diurnal tide current $u_{K_{1}}\left[\mathrm{~m} \mathrm{~s}^{-1}\right]$

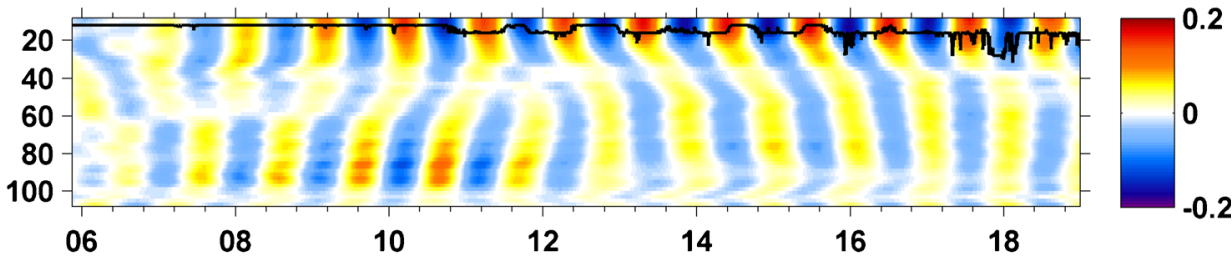

e Semi-diurnal tide current $u_{M_{2}}\left[\mathrm{~m} \mathrm{~s}^{-1}\right]$

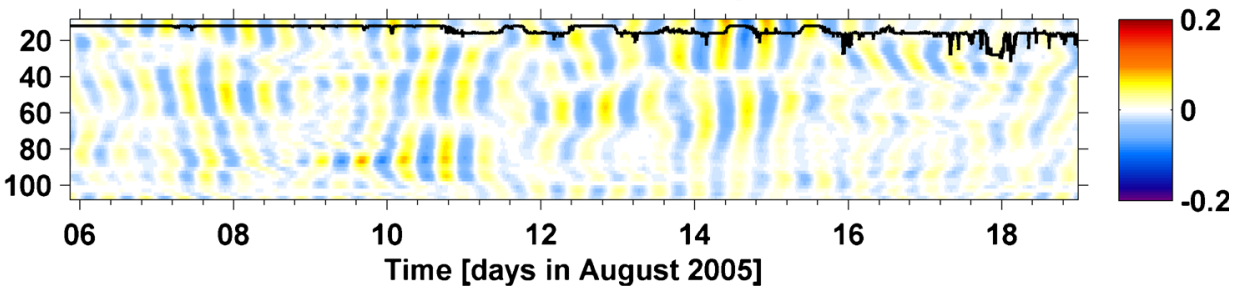

the strong wind bursts were 1.5 times greater than that of pre-wind (Figs. 4b and 5b). The oscillations generated during the strong wind bursts (10, 11, and 14 August) were near inertial (Figs. $4 c$ and $5 c$ ) and primarily of the first mode, with flow above $40 \mathrm{~m}$ opposite to the deeper flow. The details about the near-inertial waves are documented in Section 4.

Substantial changes in water properties sustained throughout the strong wind bursts since 9 August, and this situation continued for tens of hours after the strong wind on 14 August. Water depth with high temperature and low salinity deepened after the strong wind bursts (Fig. 2). The mooring temperature records obtained from thermistor sensors showed internal waves (with high temperature penetrated into as deep as $80 \mathrm{~m}$ ) occurred more frequently during the strong wind bursts (Fig. 3). The thickness of warmer water with values higher than $28^{\circ} \mathrm{C}$ increased about $15 \mathrm{~m}$ from $18 \mathrm{~m}$ pre-wind to deeper than $33 \mathrm{~m}$ after the wind blew intensively since 10 August. Near-surface salinity decreased due to the heavy rain accompanied with the strong wind bursts, dropping from 34.5 to 34.3 psu and then rose back up to 34.5 psu on the morning of 16 August. Warmer and 
Fig. 5 Same as Fig. 4 but for meridional current velocity $v$ component (north-south direction). Besides, in (c), downward migration of nearinertial oscillation is indicated with downward-sloping phase errors. The implied downward group velocity is labeled. The black line in each panel shows the mixed layer depth computed from moored temperature difference
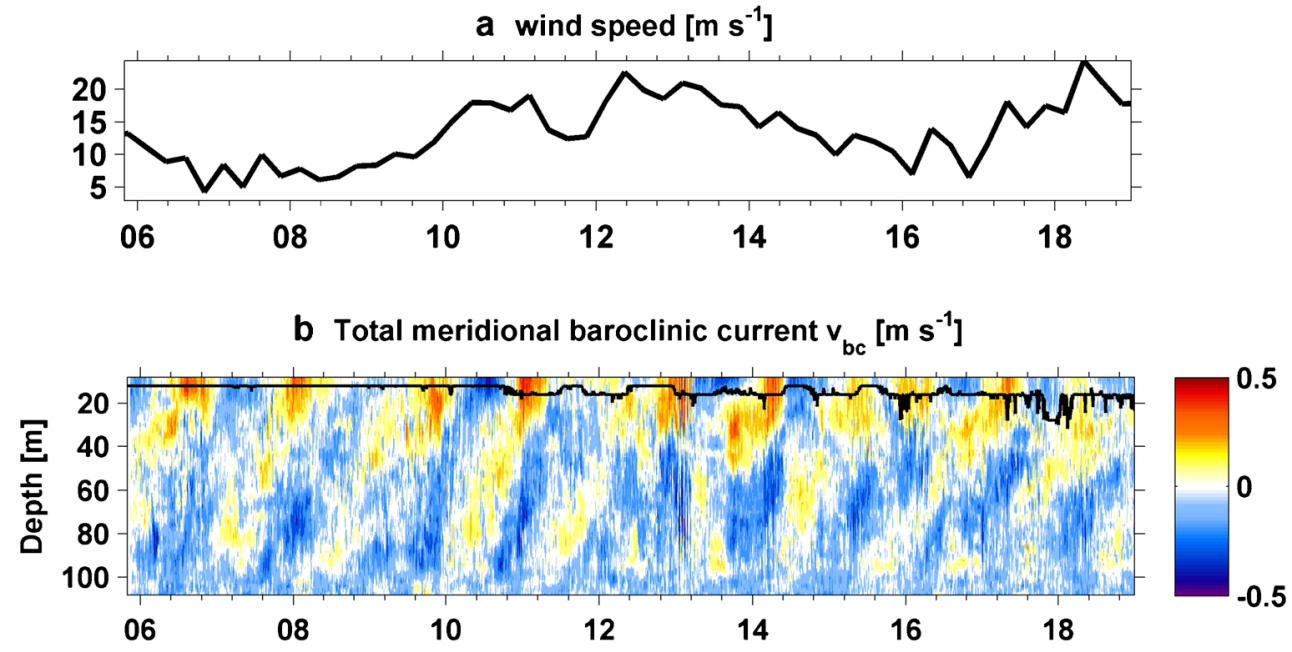

C Near-inertial current $v_{f}\left[\mathrm{~m} \mathrm{~s}^{-1}\right]$
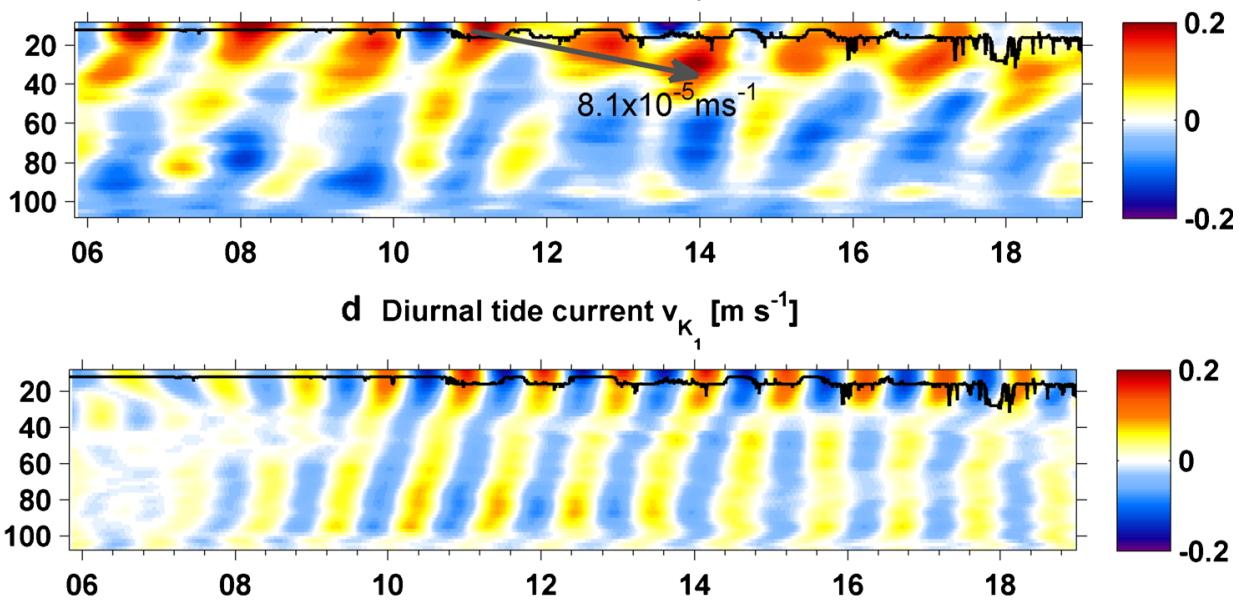

e Semi-diurnal tide current $v_{M_{2}}\left[\mathrm{~m} \mathrm{~s}^{-1}\right]$

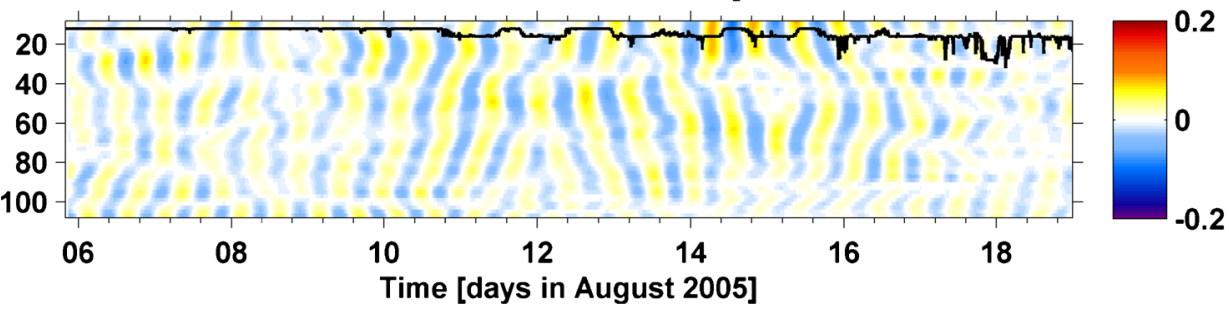

Time [days in August 2005]

fresher water with lower density stretched from the surface to about $33 \mathrm{~m}$ beginning on 11 August. From the noon of 16 August, the weather cleared up and the water properties returned to the value of pre-wind.

Changes in temperature and salinity on an isopycnal surface are often indicators of advective change. During this study, the variable stratification provided a changing environment for local internal waves and turbulence (Fig. 6a, f). Stratification tripled and underwent significant changes in vertical structure over the fortnight of observations. On a daily basis of post-wind, internal waves produced thermocline displacements of more than $40 \mathrm{~m}$ (Fig. 6f). Based on density difference criteria, we define the surface mixed layer depth as the region with a density within $0.125 \mathrm{kgm}^{-3}$ of the smallest density. The surface layer mixed downward (Fig. 2) after the strong wind bursts. Average surface mixed layer thickness was $13.4 \mathrm{~m}$ pre-wind and $22.4 \mathrm{~m}$ post-wind. The gradients of temperature before 9 August was larger than that after 11 August (Fig. 3) near the surface. The apparent decrease of temperature gradients after the strong wind 
Fig. 6 The left panels are the data of pre-wind. a The buoyancy frequency $N^{2}(4 \mathrm{~m}$ smoothed), b $4 \mathrm{~m}$ shear variance $S^{2}$ calculated from current velocity $u$ and $v$, $\mathbf{c}$ inverse Richardson number $\mathrm{Ri}^{-1}$ (the black contour indicates the critical value $\mathrm{Ri}^{-1}=4.0$ for shear instability), d TKE dissipation rate $\epsilon$ labeled with the sea surface mixed layer depth (black thick line), e diffusivity $\kappa_{\rho}$ calculated from Eq. 2, and the sea surface mixed layer depth was labeled (black thick line). The right panels are the same variables as the left ones, but for the data of post-wind
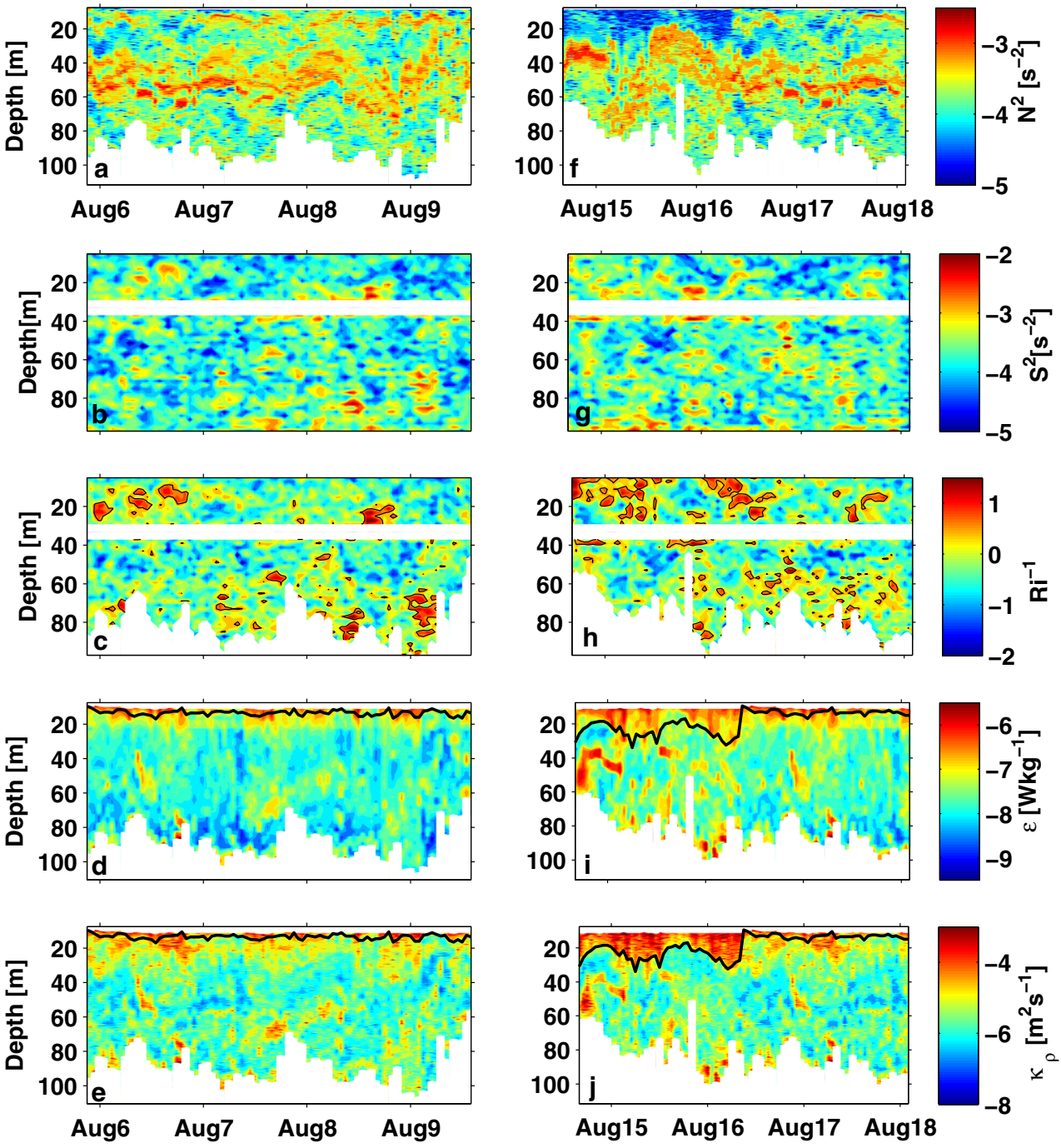

bursts indicating the strong mixing process during and after the strong wind.

\section{Observations on turbulent mixing}

As mentioned previously in Section 2, the entire water column was not covered by the TurboMapII profiler. The limited number of microstructure profiles that extended deeper than $90 \mathrm{~m}$ revealed high kinetic energy dissipation rate near the bottom boundary layer (Fig. 6d, i). To better understand the response of ocean mixing at different depths away from boundaries, turbulence observations were subdivided into the following three layers: turbulence in the surface mixed layer (as defined in the previous section), in the interior (below the surface mixed layer and above $60 \mathrm{~m}$ ), and in the intermediate layer $(60-80 \mathrm{~m})$.

Surface forcing produced large turbulent dissipation rate in the surface mixed layer (Fig. 7a, b), resulting the increase of surface mixed layer thickness (Fig. 6). According to the statistics of turbulent dissipation rate $\epsilon$ in different layers shown in Fig. 8, $9.33 \% \epsilon$ of pre-wind was larger than $10^{-6} \mathrm{~W} \mathrm{~kg}^{-1}$ and $37.9 \% \epsilon$ of post-wind was larger than $10^{-6} \mathrm{~W} \mathrm{~kg}^{-1}$ in the surface mixed layer. Thirty-two percent of post-wind and $21.9 \%$ of pre-wind were larger than $5 \times 10^{-8} \mathrm{Wkg}^{-1}$ in the interior layer, respectively. The percentage of $\epsilon$ which was larger than $5 \times 10^{-8} \mathrm{Wkg}^{-1}$ in the interior layer is $39.5 \%$ if we only consider the first $48 \mathrm{~h}$ of post-wind (the red line in Fig. 8b). Percentages of $16.1 \%$ of pre-wind and $35.8 \%$ of post-wind were larger than $5 \times 10^{-8} \mathrm{Wkg}^{-1}$ in the intermediate layer, respectively. Mean values of $\epsilon$ differ by about a factor of 2.5 to 4 between the pre-wind and post-wind. It is reasonable to conclude that the enhanced mixing below the mixed layer correlated to the strong wind bursts.

The notably high turbulent dissipation rate that appeared in the interior and intermediate layer (e.g., on 6, 7, 14, 15 , and 16 August) varied consistently with stratification 

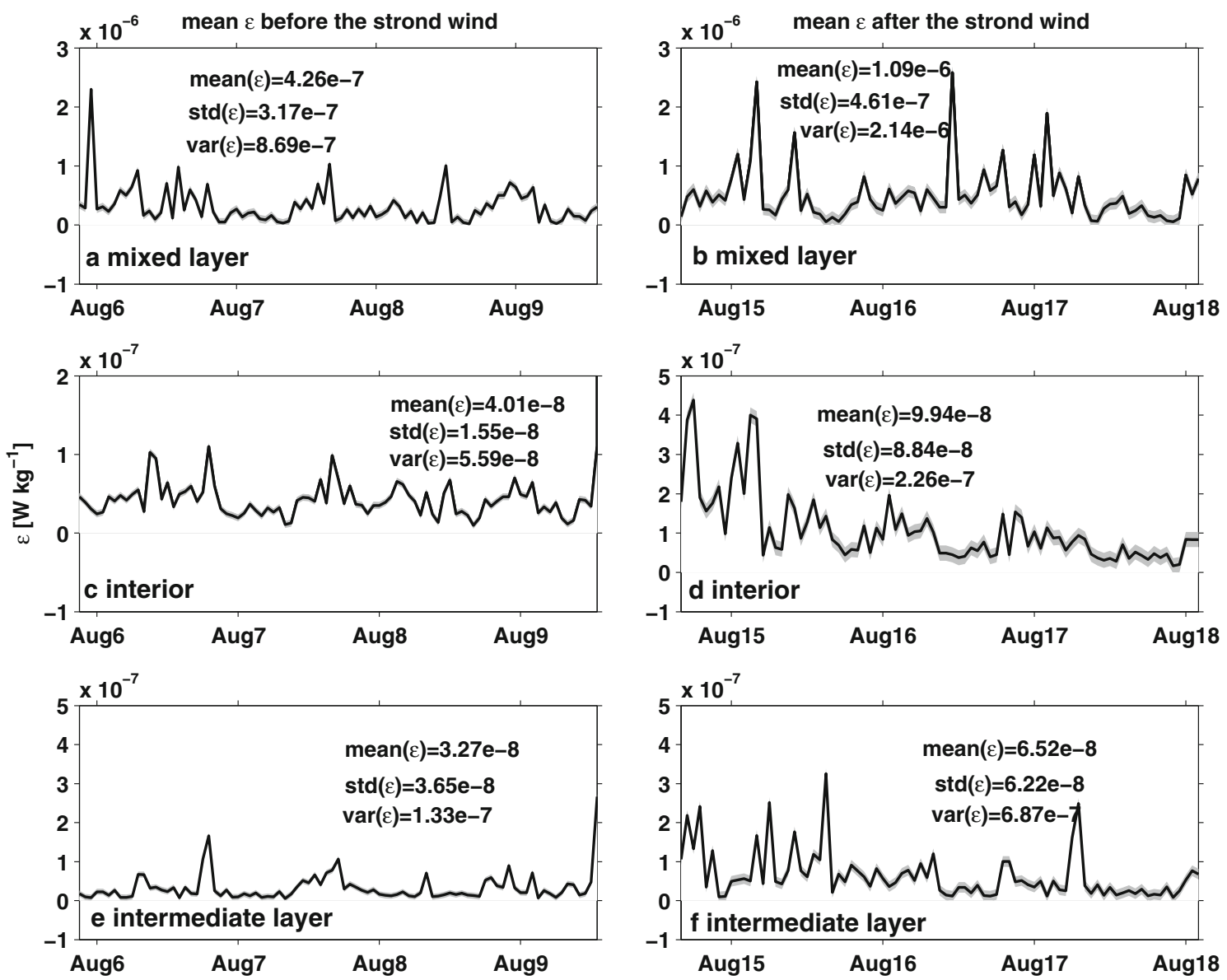

Fig. 7 The depth averaged values of $\epsilon$ in different layers. The left panels are for the pre-wind. a Mean $\epsilon$ in the surface mixed layer, $\mathbf{c}$ mean $\epsilon$ in the interior layer, e mean $\epsilon$ in the intermediate layer. The right

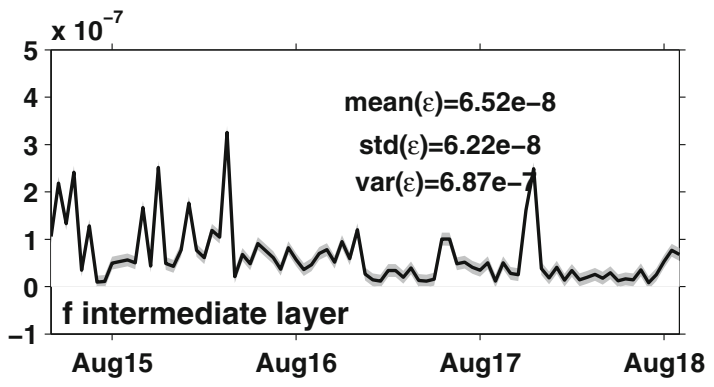

panels are the same but for the data of post-wind. Values of mean, standard deviation, and variation of $\epsilon$ are labeled in each panel

and shear variances (Fig. 6). To detect the relationship between ocean mixing and shear variance and stratification, the inverse Richardson number $\mathrm{Ri}^{-1}$ often is used to link dynamic instabilities and turbulence, either through direct

shear instabilities or wave-wave interaction (Kunze et al. 1990; Polzin 1996):

$\mathrm{Ri}^{-1}=S^{2} / N^{2}$
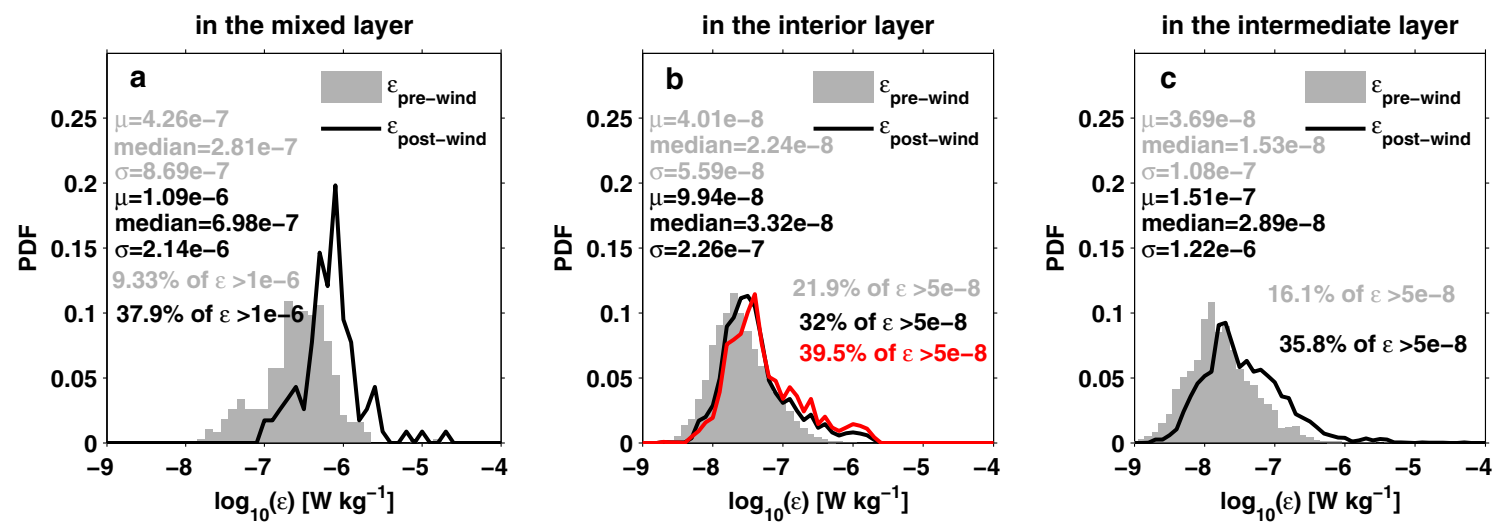

Fig. 8 Statistical probability distributions of $\epsilon$ in the three different layers of pre-wind (gray bars) and post-wind (thick lines): a the surface mixed layer, $\mathbf{b}$ the interior layer, $\mathbf{c}$ the intermediate layer. The left patches $(\mathbf{a}-\mathbf{c})$ are from pre-wind measurements and the right ones $(\mathbf{d}-$ f) are from post-wind. In (b), the red line shows the results for the first $48 \mathrm{~h}$ of post-wind 
where $N^{2}$ is buoyancy frequency (calculated from temperature and salinity). Both the theory and experiments have shown that a steady shear flow is prone to shear instability as long as the inverse Richardson number remains above 4 (Miles 1961; Thorpe 1978). $\mathrm{Ri}^{-1}$ was well above the critical standard in a patch that coincided with the high shear variance and low stratification (Fig. 6). Theoretically, if $\mathrm{Ri}^{-1}$ is larger, the wave is more prone to break which results in strong mixing.

The changes of stratification, shear, and patterns of turbulence are illustrated by comparison of the average profiles (Fig. 9) from 7-9 August (dominated by clear weather) with those from 14-15 August (when the strong wind bursts occurred). During 7-9 August (Fig. 9, thick gray line), stratification was strong especially in the surface layer, and shear variance was less than four times the average stratification (Fig. 9d); this means that the inverse Richardson number was less than 4 , indicating that turbulent mixing across the stratification was generally suppressed. The averaged turbulent dissipation rate and diffusivity were comparable in magnitude to open ocean values: Both diminished with increasing depth below the surface mixed layer, then increased again in the deeper stratified region approaching the bottom mixed layer (MacKinnon et al. 2008). Beginning on 14-15 August (Fig. 9, thin red line), the water column was significantly well-mixed and current shear variance was, on average, more than four times stratification, indicating the possibility of shear instabilities. Reinforced turbulent dissipation rate extended deeper than $60 \mathrm{~m}$ below the surface and was coincident with unstable Richardson numbers (Fig. 9d). The turbulent dissipation rate was about five times larger than the background values (Fig. 9e), indicating that ocean mixing was distinctly enhanced after the strong wind bursts. Average diffusivity profiles were calculated from the dissipation rate and stratification according to Osborn's formula (Osborn 1980),

$\kappa_{\rho} \propto 0.2 \epsilon / N^{2}$

During 7-9 August, the average diffusivity $\kappa_{\rho}$ in the thermocline and in the intermediate layer was $4.3 \times 10^{-5} \mathrm{~m}^{2} \mathrm{~s}^{-1}$, and the average $\kappa_{\rho}$ for 14-15 August was significantly enhanced to $4.0 \times 10^{-4} \mathrm{~m}^{2} \mathrm{~s}^{-1}$, which was 1 order of magnitude larger than the pre-wind value.

\section{Vertical structure and propagations of near-inertial currents}

\subsection{Summary of the observed internal waves}

During the present experiment, current velocity was primarily low-frequency, and low-mode internal waves dominated by a first-mode structure with flow above $40 \mathrm{~m}$ depth moving opposite the deeper flow (Figs. $4 \mathrm{~b}$ and $5 \mathrm{~b}$ ). The waves generated during the strong wind bursts (10-14 August) were near inertial and primarily of the first mode, with substantial second- and third-mode components. The depthintegrated baroclinic energy during the strong wind bursts on 11 and 13 August also indicated strong internal waves, which mostly disappeared after a single inertial period $(2 \pi / f \approx 36 h)$. Frequency spectral analysis shows that the baroclinic velocity was dominated by the near-inertial $(f)$, diurnal $\left(K_{1}\right)$, and semidiurnal $\left(M_{2}\right)$ tides with a peak at $1.05 f$ (Fig. 10). It is notable that the near-inertial and diurnal frequencies dominated the spectra from the sea surface

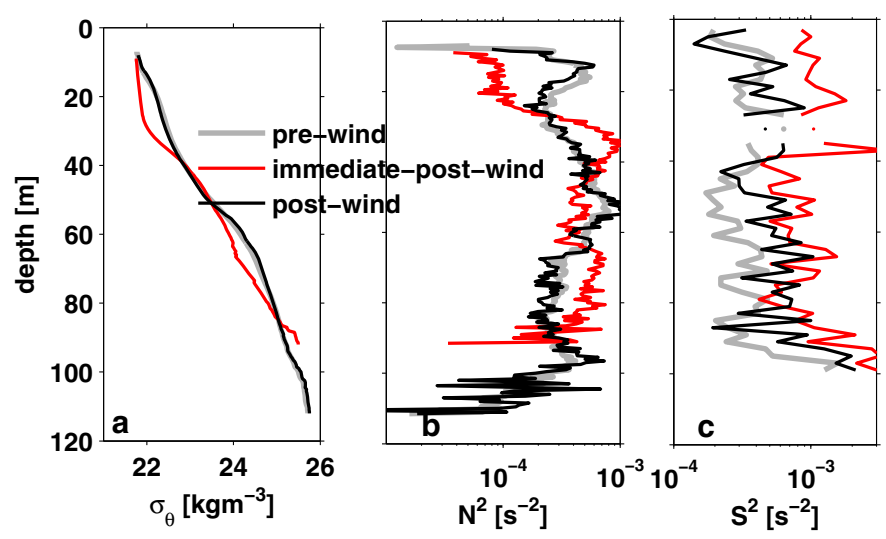

Fig. 9 Average profiles of various properties from three periods representative of the first week (August 7- 9, thick gray lines) and the second week (August 14-15, thin black lines) and the first $48 \mathrm{~h}$ of postwind (red lines): a potential density, b buoyancy frequency, $\mathbf{c}$ shear
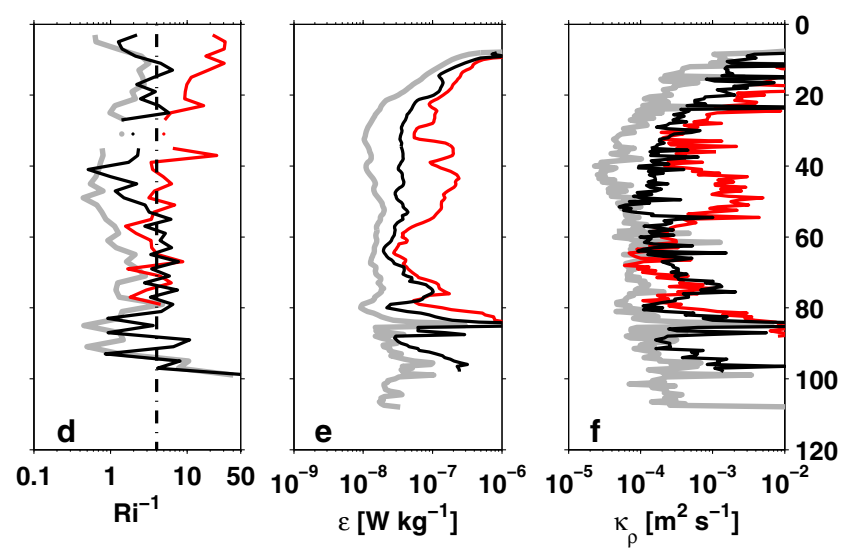

variance, $\mathbf{d}$ the inverse Richardson number, the dash line shows the critical value 4 for instabilities, e turbulent dissipation rate, and $\mathbf{f}$ diapycnal diffusivity (defined only away from well-mixed surface and bottom layers) 


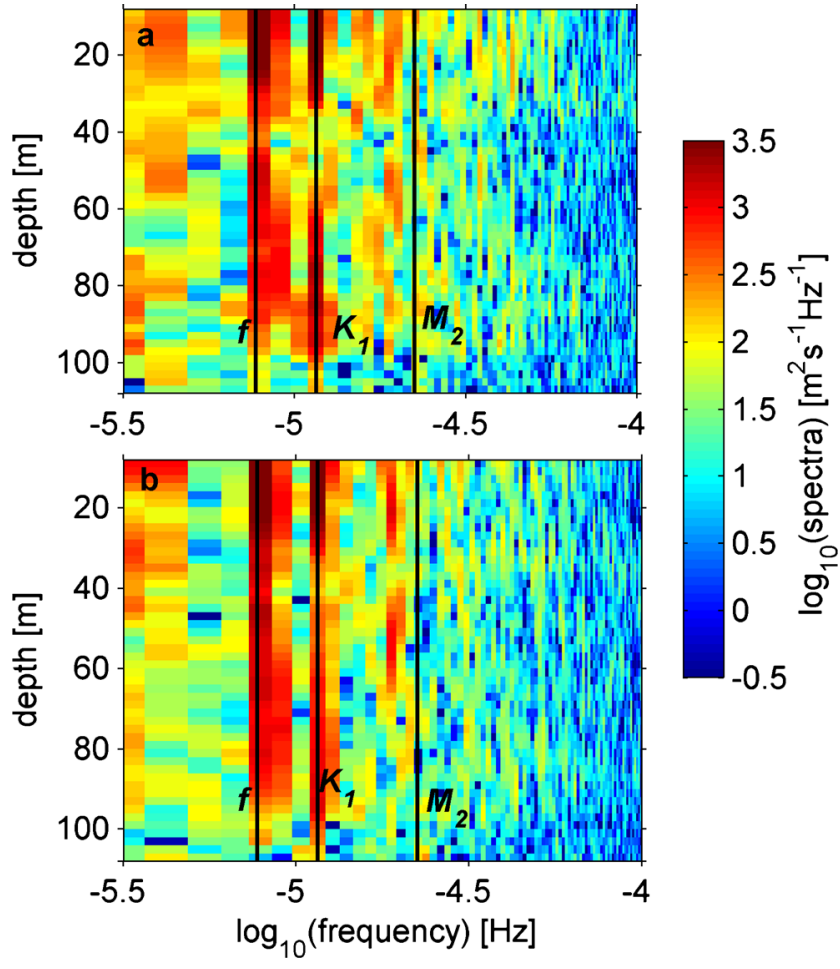

Fig. 10 The spectra of baroclinic current velocity during the whole observation period. a Spectra of zonal velocity $u$ and $\mathbf{b}$ spectra of meridional velocity $v$. The frequencies for inertial $(f)$, diurnal $\left(K_{1}\right)$, and semidiurnal $\left(M_{2}\right)$ are labeled in each panel

mixed layer to the base of the intermediate layer. The minimal spectra around $40-60 \mathrm{~m}$ during pre-wind are found to be associated with the first-mode structure.

In order to see the relationship between the enhanced near-inertial energy and turbulent dissipation rate, nearinertial currents and diurnal and semidiurnal tides are calculated through bandpass filtering by $\left[\begin{array}{ll}0.8 & 1.2\end{array}\right] \mathrm{f},[0.8$ $1.2] K_{1}$, and [0.8 1.2] $M_{2}$, respectively (Figs. 4 and 5). The corresponding horizontal kinetic energy (HKE) and shear variance for each of the filtered currents were calculated (Fig. 11). The HKE of near-inertial currents is larger than those of diurnal and semidiurnal tides, especially at depths greater than $30 \mathrm{~m}$. The average HKE of near-inertial currents below the surface mixed layer during and immediately after the strong wind bursts is about 1 order of magnitude larger than that of diurnal tides. Shear variance computed from near-inertial currents is also much larger than those from diurnal and semidiurnal tides. Moreover, the strong shear variance of near-inertial currents corresponds to the distribution of HKE both in time and space.

We examine profiles of near-inertial current velocity to find out their vertical propagations. This method has been used in previous studies (Alford 2010). During the most part of our measurement, both the near-inertial zonal and meridional velocities show upward-propagation phase, suggesting that the dominant near-inertial energy was propagated downward (Figs. 4c and 5c). According to the method utilized in Qi et al. (1995), the downward group velocity $\left(c_{\mathrm{gz}}\right)$ can be estimated via the ratio of the vertical migration of the near-inertial groups and the corresponding time period (Fig. 5c). The period of the most prominent burst of near-inertial oscillation is from early 11 August to early 14 August (about $72 \mathrm{~h}$ ) with an approximate vertical penetration depth of $21 \mathrm{~m}$. Thus, the vertical group velocity is roughly estimated to be $8.1 \times 10^{-5} \mathrm{~ms}^{-1}$.

The ratio of wind work input propagated below the mixed layer as near-inertial currents and made available for ocean mixing is an important issue. Wind work was calculated via wind stress $\tau$ multiplied by near-inertial current velocity vector. Wind stress was computed from the NCEP reanalysis wind speed data shown in Fig. 2a. Due to the limits of our observed data, we estimate the vertical energy flux via downward group velocity of near-inertial currents multiplied by near-inertial current horizontal kinetic energy from the intermediate layer (Alford et al. 2012). The average downward group velocity $\left(c_{\mathrm{gz}}=8.1 \times 10^{-5} \mathrm{~ms}^{-1}\right)$ during the strong wind bursts is chosen for calculating the energy flux. Both the wind work and energy flux were averaged for inertial period $(\approx 36 \mathrm{~h})$. The percentage of wind work transmitted into the intermediate layer is highly variable in time (Fig. 11a). With mean values during the strong wind bursts, about $4.2 \%$ of wind work propagated into the intermediate layer.

\subsection{Near-inertial currents propagate downward}

In order to discuss the time variations of near-inertial wave energy propagation in the vertical direction, vector spectral analysis is used here. Following Leaman and Sanford (1975), the horizontal current velocity vector can be written as $u(z)+i v(z)$, where $u$ is the real (east) part of the horizontal velocity and $v$ is the imaginary (north) part. The velocity vector at each vertical wave number $m$ can be separated into positive and negative components,

$u_{m}+i v_{m}=u_{+} e^{i m z}+u_{-} e^{-i m z}$

where $u_{-}$and $u_{+}$are the clockwise and anticlockwise components, respectively. The corresponding vector spectra are the following:

$C_{m}=\frac{1}{2}<u_{-}^{*} u_{-}>, A_{m}=\frac{1}{2}<u_{+}^{*} u_{+}>$

where $C_{m}$ is the clockwise part indicating upward velocity and downward group velocity, and $A_{m}$ is the anticlockwise part indicating downward velocity and upward group velocity. We calculate the $C_{m}$ and $A_{m}$ of the unfiltered baroclinic current, near-inertial current, diurnal current, and 
Fig. 11 a Surface wind work (black line) and the energy flux (gray line) computed as the mean near-inertial horizontal kinetic energy from intermediate layer multiplied by

$c_{\mathrm{gz}}=8.1 \times 10^{-5} \mathrm{~ms}^{-1}$. All

have been smoothed over inertial period. b Horizontal kinetic energy for near-inertial current. c Horizontal kinetic energy for diurnal current. $\mathbf{d}$ Horizontal kinetic energy for semidiurnal current. e Velocity shear variance for near-inertial current. f Velocity shear variance for diurnal current. $\mathbf{g}$ Velocity shear variance for semidiurnal current. Black lines in panels $(\mathbf{b}-\mathbf{g})$ show the mixed layer depth computed from the moored temperature difference

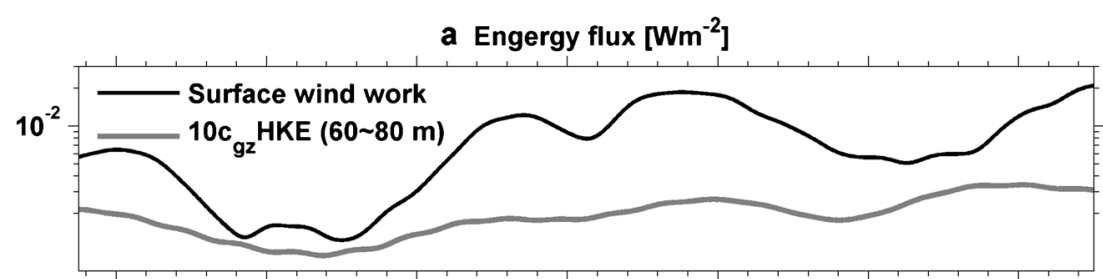

b Near-inertial H.K.E. $\left[\mathrm{m}^{2} \mathrm{~s}^{-2}\right]$

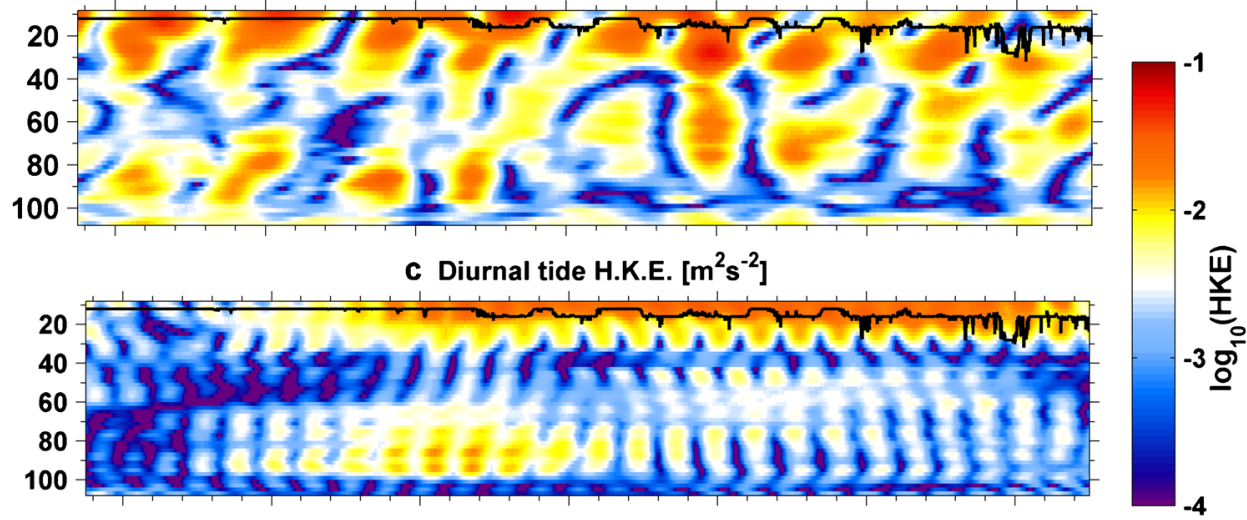

d Semi-diurnal tide H.K.E. $\left[\mathrm{m}^{2} \mathrm{~s}^{-2}\right]$

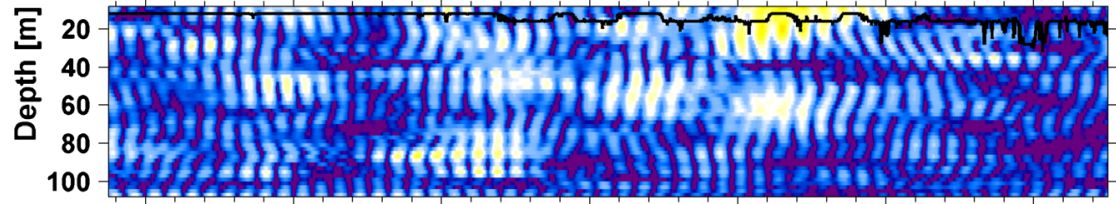

e Near-inertial shear variance $\left[\mathbf{s}^{-2}\right]$

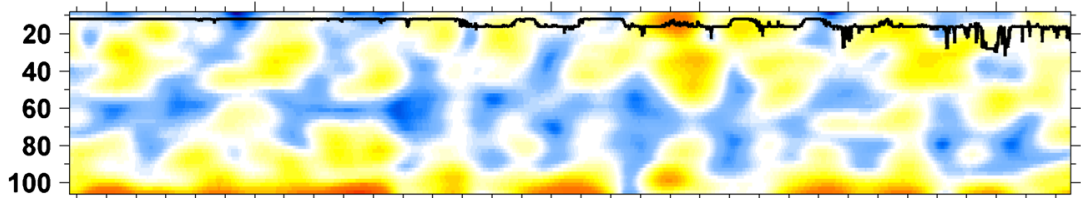

f Diurnal shear variance $\left[\mathrm{s}^{-2}\right]$

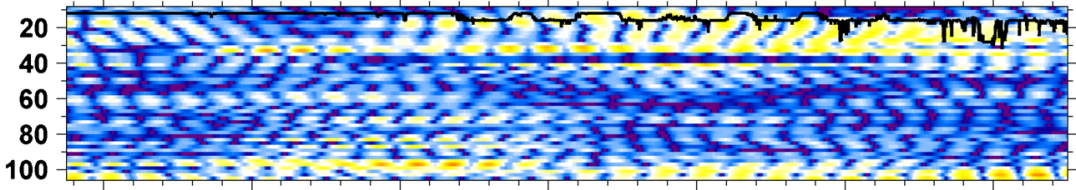

g Semi-diurnal shear variance $\left[\mathrm{s}^{-2}\right.$ ]

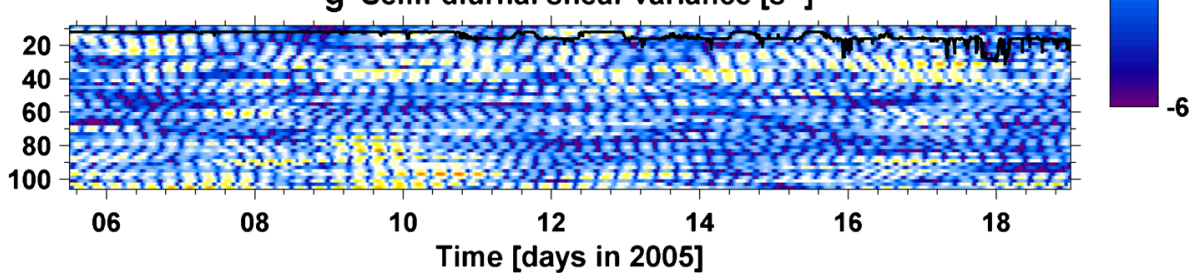

$-3$ semidiurnal current, respectively (Fig. 12). If we define $D_{m}=C_{m}-A_{m}$, then net energy that propagates downward as $D_{m}$ is positive and net energy that propagates upward as $D_{m}$ is negative. The distribution of vector spectra calculated from the averaged baroclinic currents from 14 to 16 August indicates that near-inertial currents propagated 
downward (Fig. 12b), but there is no evidence showing distinct downward or upward energy propagation of the diurnal and semidiurnal tides (Fig. 12c, d). Positive $D_{m}$ means that net energy propagates downward, and the energy source is at the sea surface. Near-inertial currents probably provided an effective channel for energy propagation from the sea surface layer into the ocean's interior.

Depth mean $D_{m}$ was calculated from hourly averaged near-inertial, diurnal, and semidiurnal tides (Fig. 13). The distribution shows that $D_{m}$ calculated from the near-inertial current was close to zero before the strong wind bursts, and $D_{m}$ was elevated to a value about four times larger about 1.5 inertial periods after the strong wind bursts occurred.

\subsection{High-mode near-inertial currents strengthened}

The waves that arose after the strong wind bursts had a higher-mode structure, with peaks in velocity in the upper $40 \mathrm{~m}$ and near $70 \mathrm{~m}$. As discussed above, the mean value of baroclinic HKE during and after the strong wind bursts was about $6.0 \times 10^{-3} \mathrm{Jkg}^{-1}$, which was two times larger than the pre-wind averaged value. Peak shear variance of nearinertial currents (about $1.0 \times 10^{-3} \mathrm{~s}^{-2}$ ) matched the distribution of near-inertial HKE both in time and space (Fig. 11b, e). In order to find out the relationship between the energy increase of near-inertial currents and currents with different modes structure, a method for vertical mode decomposition is used. A linear wave field can be represented as a superposition of internal waves of distinct frequency and vertical mode number $(j)$, which together determine the magnitude of horizontal wave number (Levine 2002). The vertical structure of each mode is governed by the following equations (Thorpe 1998):

$\Psi_{j}^{\prime \prime}(z)=-\frac{N^{2}(z)}{c_{j}^{2}} \Psi_{j}(z)$
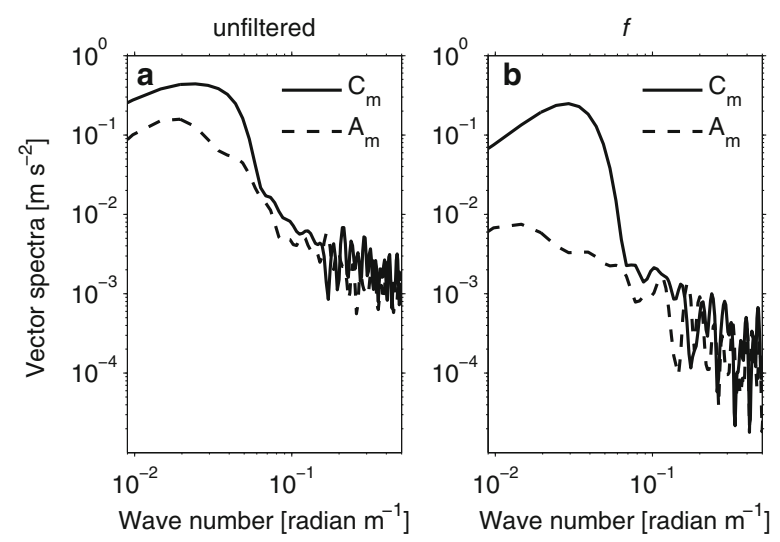
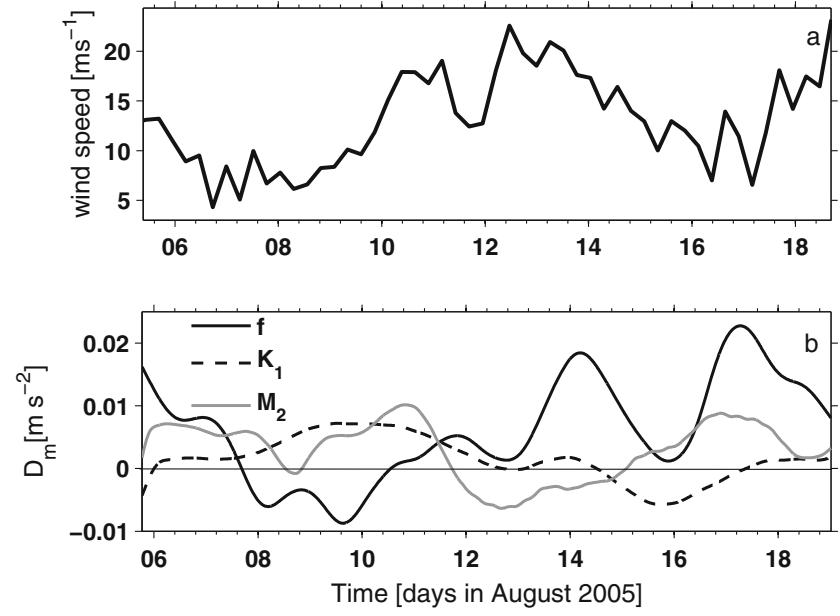

Fig. 13 a Wind speed during the observation and $\mathbf{b}$ the depth integrated vector spectra $D_{m}$ of near-inertial current (black solid line), diurnal current (black dashed line), and semidiurnal current (gray solid line), respectively

$\Psi_{j}(-H)=\Psi_{j}(0)=0$

where $c_{j}$ is the separation constant (eigenvalue), and waves are assumed to be hydrostatic. Vertical velocity and vertical displacement associated with each mode are proportional to $\Psi_{j}$, whereas the horizontal velocity is proportional to $\frac{d \Psi_{j}}{d z}$. The vertical mode shapes are shown in Fig. 14. A mode fit velocity profile was calculated by combining the projected amplitude and vertical structure of the first five baroclinic modes. Figure 15 shows examples of the mode fit for eastward and northward velocity of pre-wind, during strong wind bursts, and post-wind, respectively. The mode fit captures $92 \%$ of the baroclinic energy and $80 \%$ of the shear variance.

The modal repartitions for HKE and shear variance of near-inertial current, diurnal current, and semidiurnal current are calculated, respectively (Fig. 16). Generally, the
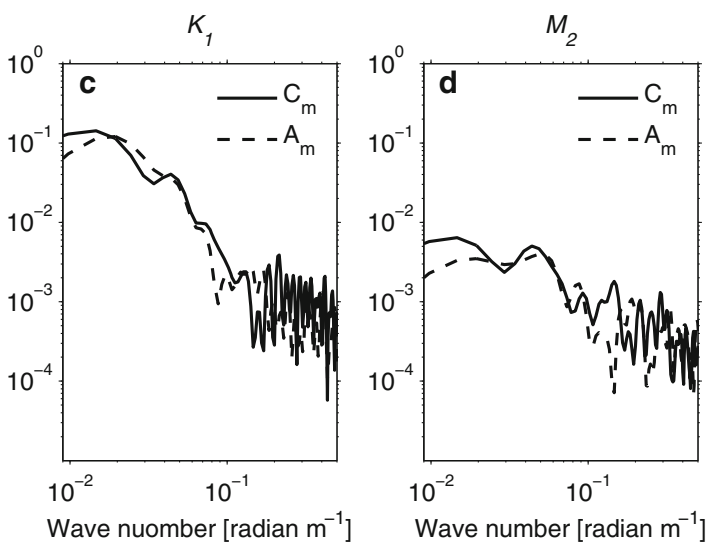

Fig. 12 Vector spectra of a unfiltered current, b near-inertial current, $\mathbf{c}$ diurnal current, and $\mathbf{d}$ semidiurnal current, respectively. Solid line stands for the clockwise part, and dash line stands for the anticlockwise part. The chosen current is the averaged from Aug. 14 to Aug. 16 (immediately after the storm) 

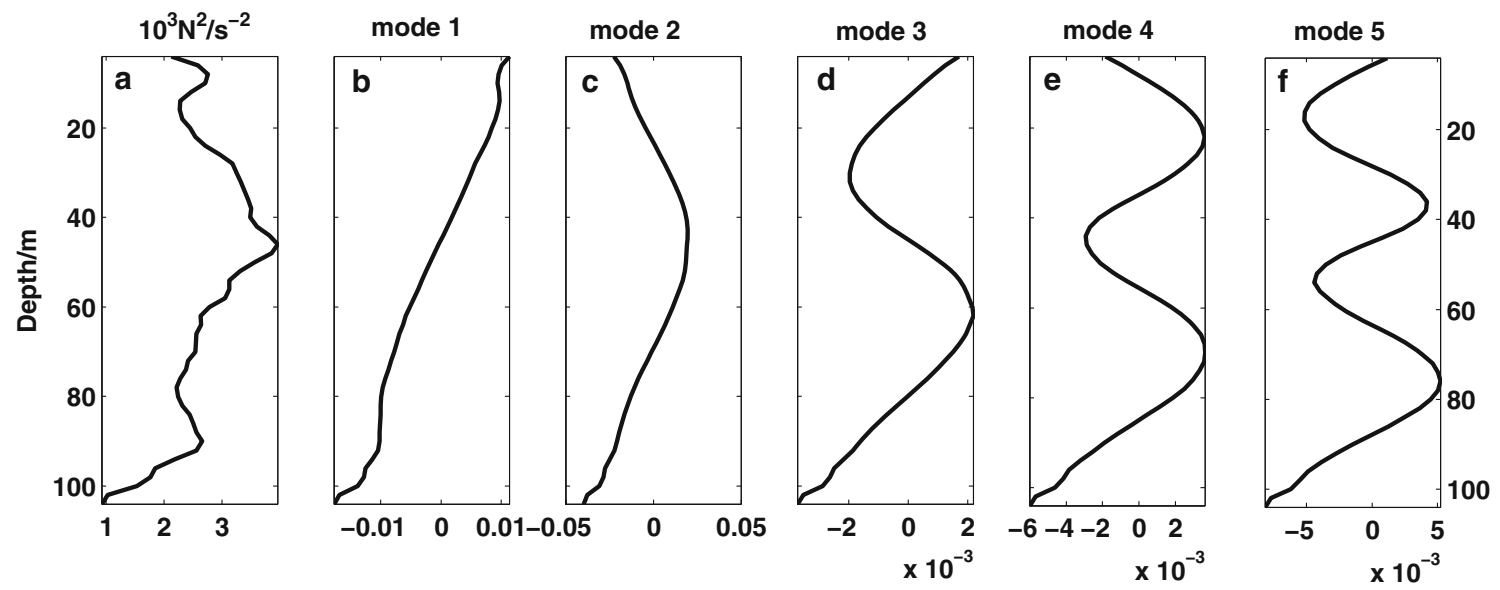

Fig. 14 a Cruise-averaged stratification, $\mathbf{b}-\mathbf{f}$ are different vertical mode shapes

partitioning of HKE for tidal currents between modes is dominated by the contribution from the higher 3 modes, which contain approximately $87 \%$ of the total HKE in the tidal current band (Fig. 16b, c). The ratio between different modes for tidal currents changes little during the whole obervation. The partitioning of shear variance for tidal currents displays the similar characteristics (Fig. 16e, f). However, the changes for the modal repartition of nearinertial current are more complicated (Fig. 16a, d). From 11-18 August, energy and shear variance in higher modes increased, and during this time, the wind speed was typically strong or changed frequently (Fig. 16a). It is found that
Fig. 15 Comparison between observed current velocity and mode decomposition. a-c Stand for $u$ component of observation (solid line) and first five vertical mode results (dash line) of pre-wind, during wind and post-wind. $\mathbf{d}-\mathbf{f}$ Are the same content of $v$ component
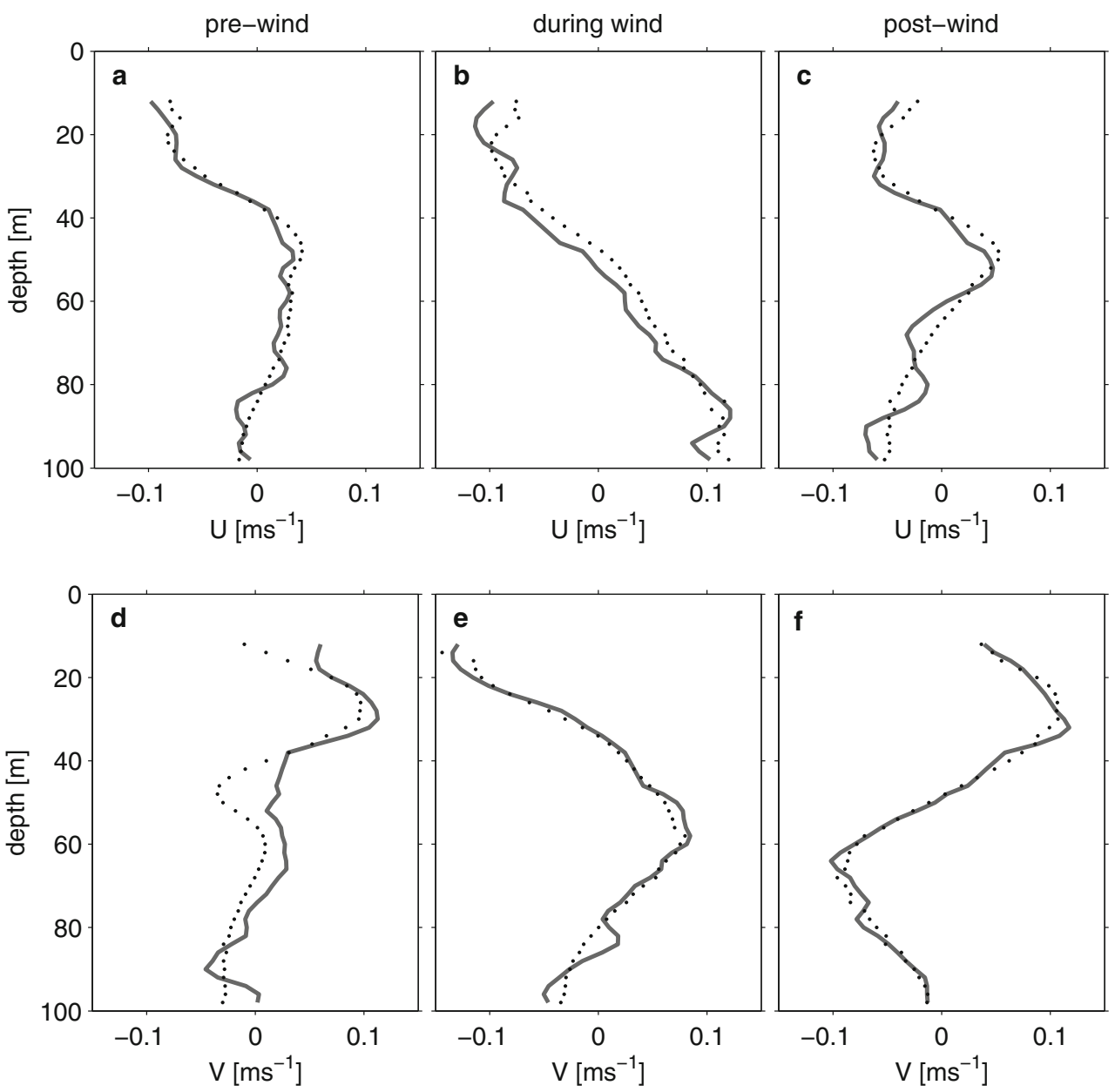
Fig. 16 The distribution of horizontal kinetic energy and shear variance for the first 4 modes. a HKE for the near-inertial current, $\mathbf{b}$ HKE for the diurnal current, $\mathbf{c}$ HKE for the semidiurnal current, $\mathbf{d}$ shear variance for the near-inertial current, e shear variance for the diurnal current, $\mathbf{f}$ shear variance for the semidiurnal current. The dark gray areas show the total energy and shear variance. It should note that the $y$-axis limits are different
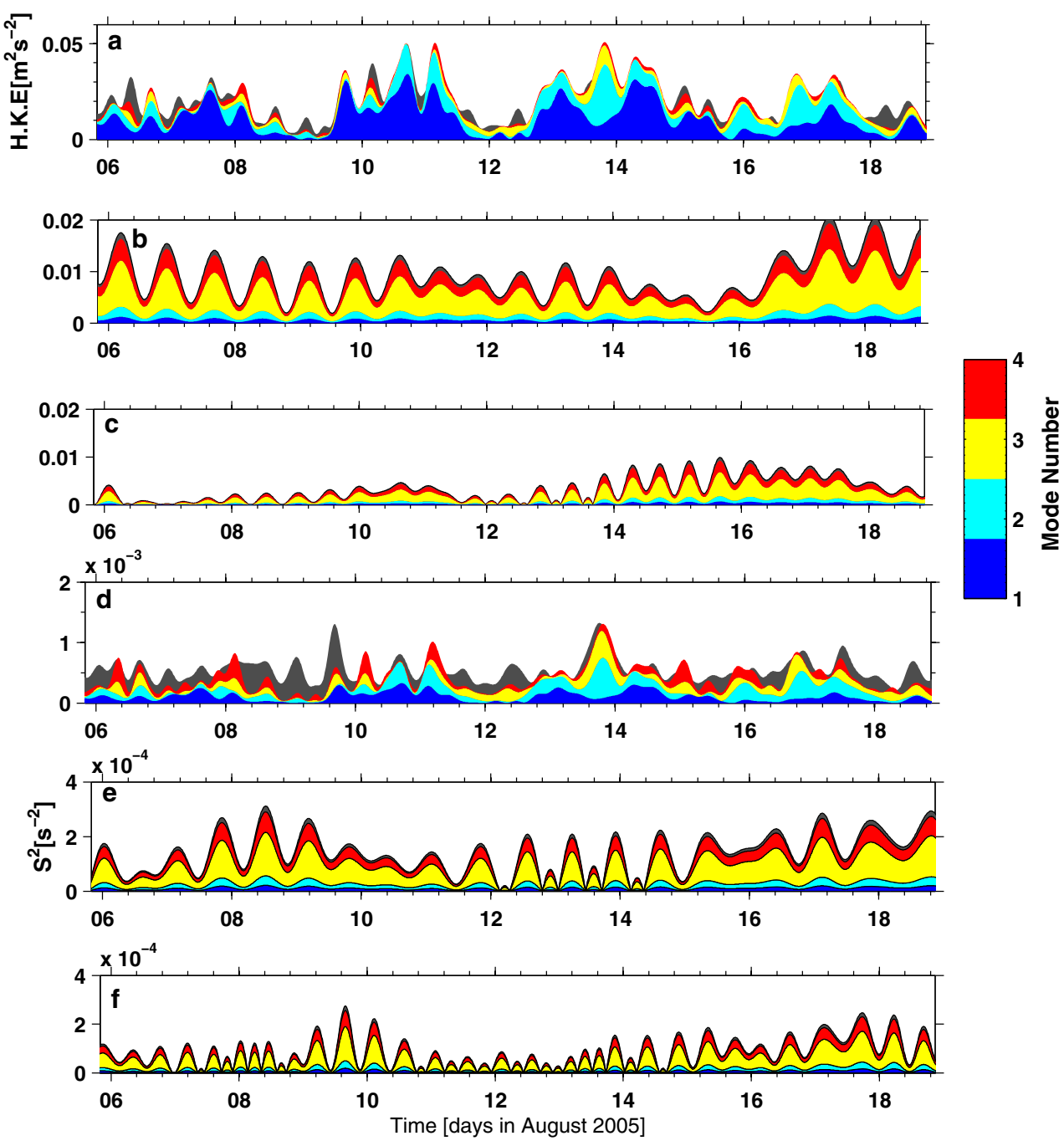

the energy and shear variance changed simultaneously. For example, the first mode was dominant on 7 August (about 82 and $68 \%$ of energy and shear variance, respectively, is contained within the first four modes); higher modes arose on 11 August and reached a maximum late on 13 August. The dominant contributor to shear variance changed from mode 1 on 10 August to modes 2 and 3 between 11 and 18 August. For near-inertial currents, higher modes contribute relatively more to shear variance than to energy, which indicates that the energy input by strong sea surface forces is prone to dissipate via the higher mode shear variance created at the same time.

\section{Summary and discussion}

We have presented the first direct observation of turbulence on the SCS shelf made during a 14-day cruise under strong wind and heavy rain weather condition. The turbulent dissipation rate was enhanced both in the mixed layer and below after the strong wind. A likely source for the enhanced turbulence is the downward-propagating near-inertial internal waves. According to the estimates of surface wind work and energy flux in the intermediate layer, about $4.2 \%$ of wind work propagated into the intermediate layer. In particular, the higher modes contribute more to shear variance than HKE, which means that the near-inertial energy input dissipates mainly through high-mode shear instabilities. Unfortunately, due to the limited measurements, a reliable method to parameterize the mixing cannot be given in this study. More detail measurements are required before establishing a reliable parameterization.

Numerous formulas which are partly empirical or based on dynamic models have been proposed to relate turbulent dissipation rate, stratification, shear, or Richardson number (Price et al. 1986; Polzin 1996; MacKinnon and Gregg 2005b) by dimensional scaling. Since the measurements described in MacKinnon and Gregg (2005a) are very similar with our situation in this paper, the parameterization method given by MacKinnon and Gregg (2005a) is used to 
Fig. 17 Dissipation rate $\epsilon$ averaged in logarithmically evenly spaced bins of shear and stratification. The $\mathrm{Ri}=0.25$ line is contoured for reference. a Observed $\epsilon$ of pre-wind, b observed $\epsilon$ of post-wind, $\mathbf{c} \epsilon$ calculated based on Eq. 7 of pre-wind, and $\mathbf{d} \epsilon$ calculated based on Eq. 7 of post-wind
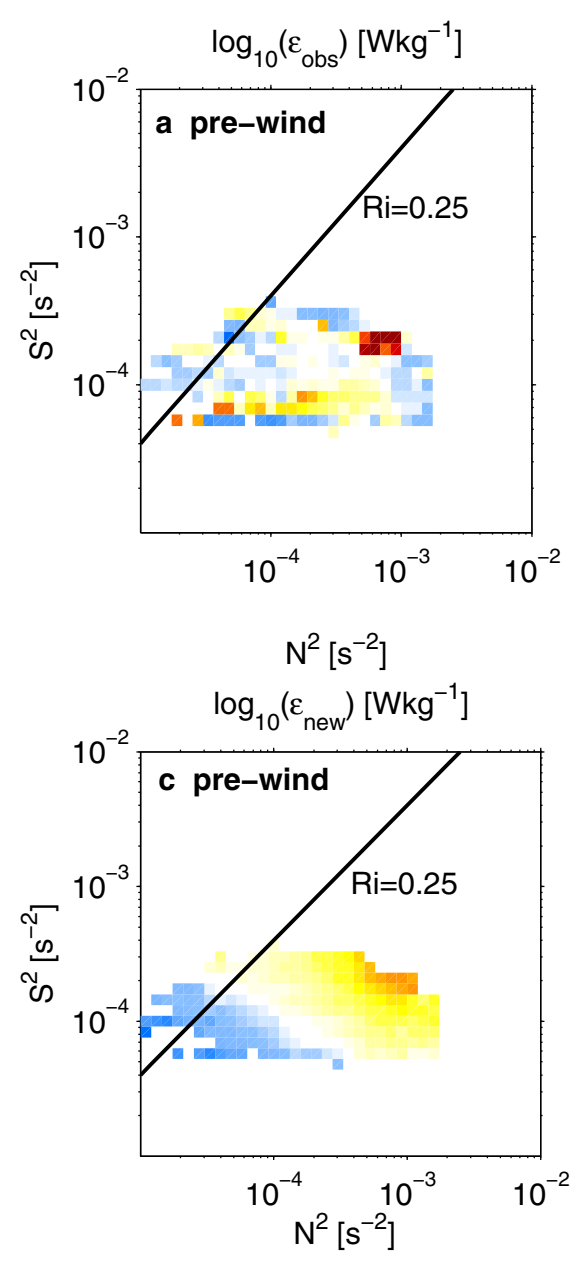

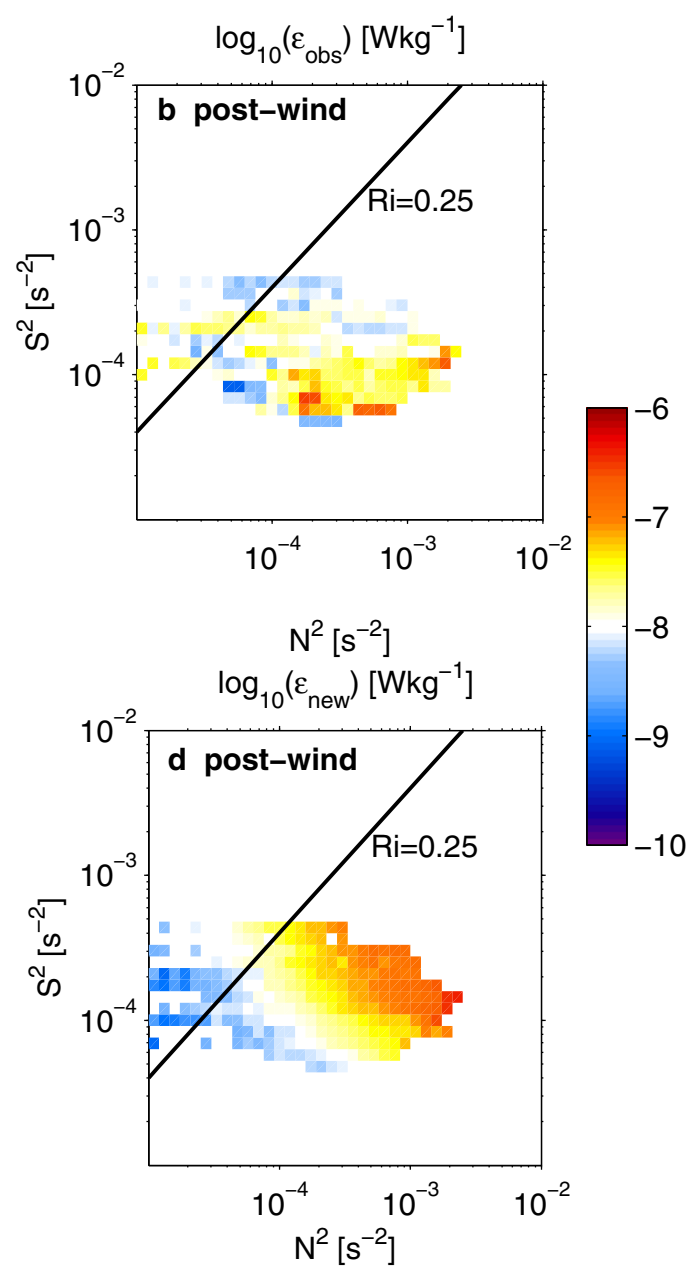

compare with our observed data. Based on their finding that the observed dissipation rate increased with both shear and stratification, MacKinnon and Gregg (2005a) proposed the scaling of the dissipation rate (hereinafter called MG05) as the following:

$\epsilon_{\text {new }}=\epsilon_{0}\left(\frac{N}{N_{O}}\right)\left(\frac{S}{S_{0}}\right)$ where $S$ is shear variance of the baroclinic currents with low-mode, $S_{0}=N_{0}=3 c p h, \epsilon_{0}=2.8 \times 10^{-11}$ is chosen in the fitting calculation. In light of the marked increase in near-inertial currents with modes higher than 1 during the strong wind bursts, we limit the shear variance to baroclinic currents with higher modes to investigate the relations between the strong wind forcing and enhanced mixing. However, the modeled dissipation rate based on MG05 is
Fig. 18 Statistical probability distributions of $\epsilon_{\text {new }} / \epsilon_{\text {obs }}$, ratio of estimated results $\epsilon_{\text {new }}$ based on Eq. 7 and observed turbulent dissipation rate $\epsilon_{\mathrm{obs}}$ in the interior layer. a Pre-storm and $\mathbf{b}$ post-storm. And each panel is listed with the percentage of data pairs that are within factors of 2,5 , and 10 of each other

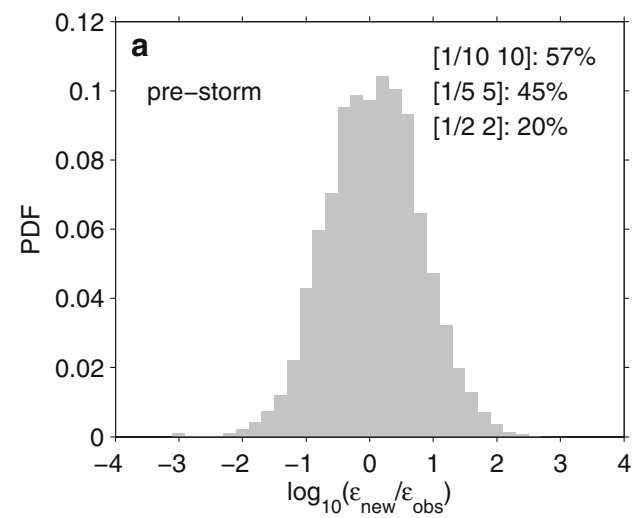


not appropriate when shear is unstable. Our measurement indicated that the dissipation rate varied inversely with stratification for a given level of shear, and this was particularly apparent after the strong wind bursts. However, if we only consider the data in the interior layer, dissipation rate more likely increased with both shear and stratification (Fig. 17a, b). And therefore, we only compare the results in the interior layer. The results calculated from the parameterization of MG05 were shown in Fig. 17c, d. A summary of the comparisons in Fig. 18 indicates that $20 \%$ of the $\left[\epsilon_{\text {obs }}, \epsilon_{\text {new }}\right]$ pairs are within a factor of 2 of each other, $45 \%$ are within a factor of 5, $57 \%$ are within a factor of 10 for the prewind (Fig. 18a). And for the post-wind (Fig. 18b), the ratios are 21,50 , and $62 \%$, respectively. This tells that the parameterization method used in MG05 can partly estimate the dissipation rate in the ocean interior for our study.

Acknowledgements The authors thank Emily Shroyer for her comments on the early version. The constructive suggestions from Dr. Zhifei Liu are really appreciated. We thank the reviewers for their valuable comments that greatly improved the submitted manuscript.

Open Access This article is distributed under the terms of the Creative Commons Attribution License which permits any use, distribution, and reproduction in any medium, provided the original author(s) and the source are credited.

\section{References}

Alford MH (2001) Internal swell generation: the spatial distribution of energy flux from the wind to mixed-layer near-inertial motions. $J$ Phys Ocean 31(8):2359-2368

Alford MH (2010) Sustained, full-water-column observations of internal waves and mixing near Mendocino escarpment. J Phys Ocean 40:2643-2660

Alford MH, Cronin MF, Klymak JM (2012) Annual cycle and the depth penetration of wind-generated near-inertial internal waves at ocean station papa in the northeast Pacific. J Phys Ocean 42(6):889-909

Alford MH, Gregg MC (2001) Near-inertial mixing: modulation of shear, strain and microstructure at low latitude. J Geophys Res 106(C8):16,947-16,968

Chu PC, Edmons NL, Fan C (1999) Dynamical mechanisms for the South China Sea seasonal circulation and thermohaline variabilities. J Phys Ocean 29:2971-2989

Cuypers Y, Vaillant X, Bouruet-Aubertot P, McPhaden M (2013) Tropical storm-induced near-inertial internal waves during the cirene experiment: energy fluxes and impact on vertical mixing. $\mathrm{J}$ Geophys Res 118:358-380

D'Asaro EA (2003) The ocean boundary layer below Hurricane Dennis. J Phys Ocean 33:561-579

D'Asaro EA, Eriksen CC, Levine MD, Niiler P, Paulson CA, Meurs PV (1995) Upper-ocean inertial currents forced by a strong storm. Part I: data and comparisons with linear theory. J Phys Ocean 25:2909-2936

D'Asaro EA, Perkins H (1984) A near-inertial internal wave spectrum for the Sargasso Sea in late summer. J Phys Ocean 14:489-505

Dohan K, Davis R (2011) Mixing in the transition layer during two storm events. J Phys Ocean 41:42-66

Garrett C (2003) Internal tides and ocean mixing. Science 301:18581859
Gill AE (1984) On the behavior of internal waves in the wake of a storm. J Phys Ocean 14:1129-1151

Grant ALM, Belcher SE (2011) Wind-driven mixing below the oceanic mixed layer. J Phys Ocean. doi:10.1175/JPO-D-10-05020.1

Gregg MC (1989) Scaling turbulent dissipation in the thermocline. J Geophys Res 94(C7):9686-9698

Kunze E (1985) Near-inertial wave propagation in geostrophic shear. J Phys Ocean 15:544-565

Kunze E, III AW, Briscoe M (1990) Observations of shear and vertical stability from a neutrally-buoyant float. J Geophys Res 95:1812718142

Leaman KD, Sanford TB (1975) Vertical energy propagation of inertial waves: a vector spectral analysis of velocity profile. J Geophys Res 80(15):833-846

Levine MD (2002) A modification of the Garrett-Munk internal wave spectrum. J Phys Ocean 32:3166-3181

MacKinnon JA, Gregg M (2005a) Near-inertial waves on the new england shelf: the role of evolving stratification, turbulent dissipation, and bottom drag. J Phys Ocean 35(12):2408-2424

MacKinnon JA, Gregg M (2005b) Spring mixing: turbulence and internal waves during restratification on the New England Shelf. J Phys Ocean 35(12):2425-2443

MacKinnon JA, Johnston TMS, Pinkel R (2008) Strong transport and mixing of deep water through the southwest Indian Ridge. Nat Geosci 1:755-758

Miles JW (1961) On the stability of heterogeneous shear flows. J Fluid Mech 10:496-508

Moum JN, Farmer D, Smyth W, Armi L, Vagle S (2003) Structure and generation of turbulence at interfaces strained by internal solitary waves propagating shoreward over the continental shelf. J Phys Ocean 33:2093-2112

Nash JD, Kunze E, Toole JM, Schmitt R (2004) Internal tide reflection and turbulent mixing on the continental slope. J Phys Ocean 34:1117-1134

Osborn TR (1980) Estimates of the local rate of vertical diffusion from dissipation measurements. J Phys Ocean 10:83-89

Polzin K (1996) Statistics of the Richardson number: mixing models and finestructure. J Phys Ocean 26:1409-1425

Price JF (1981) Upper ocean response to a hurricane. J Phys Ocean 11:153-175

Price JF, Weller RA, Pinkel R (1986) Diurnal cycling: observations and models of the upper ocean response to diurnal heating, cooling and wind mixing. J Geophys Res 91:8411-8427

Qi H, Szoeke R, Paulson C (1995) The structure of near-inertial waves during ocean storms. J Phys Ocean 25:2853-2871

Sandstrom H, Elliot J (1984) Internal tide and solitons on the scotian shelf: a nutrient pump at work. J Geophys Res 89:6415-6426

Sharples J, Moore CM, Abraham ER (2001) Internal tide dissipation, mixing, and vertical nitrate flux at the shelf edge of NE New Zealand. J Geophys Res 106(C7):14069-14081

Thorpe SA (1978) On the shape and breaking of finite amplitude internal gravity waves in a shear flow. J Fluid Mech 85:7-32

Thorpe SA (1998) Estimating internal waves and diapycnal mixing from conventional mooring data in a lake. Limnol Oceanogr 43:936-945

van der Lee E, Umlauf L (2011) Internal wave mixing in the Baltic Sea: near-inertial waves in the absence of tides. J Geophys Res 116:C10016. doi:10.1029/2011JC007072

Watanabe M, Hibiya T (2002) Global estimates of the wind-induced energy flux to inertial motions in the surface mixed layer. Geophys Res Lett 29(8). doi:10.1029/2001GL014422

Wolk F, Yamazaki H, Seuront L, Lueck RG (2002) A new free-fall profiler for measuring biophysical microstructure. J Atmos Ocean Technol 19(5):780-793

Wunsch C., Ferrari R. (2004) Vertical mixing, energy, and the general circulation of the oceans. Ann Rev Fluid Mech 136:281-314 